\title{
Discovery of Novel 3,4-Dichloroisothiazole-Containing Coumarins as Fungicidal Leads
}

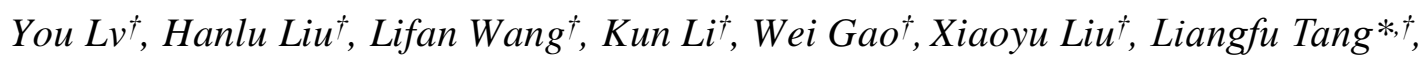
Tatiana A. Kalinina ${ }^{\ddagger}$, Tatiana V. Glukhareva ${ }^{\ddagger}$ Zhijin Fan ${ }^{*}{ }^{\dagger}$

$\dagger$ State Key Laboratory of Elemento-Organic Chemistry, College of Chemistry, Nankai University, Tianjin 300071, P. R. China.

$\$$ The Ural Federal University Named after the First President of Russia B. N. Yeltsin, Yeltsin UrFU 620002, Ekaterinburg, Russia.

* Address correspondence to this author at State Key Laboratory of Elemento-Organic Chemistry, College of Chemistry, Nankai University, No. 94, Weijin Road, Nankai District, Tianjin 300071, P. R. China (telephone +86-23499464; Fax: +86 022-23503620; e-mail: fanzj@nankai.edu.cn (for Zhijin Fan) or $\underline{\text { lftang@ @ankai.edu.cn (for Liangfu Tang) }}$

\section{Supporting Information}

Crystal data and structure refinement for compounds $7 \mathbf{e} \& \mathbf{7 r} \ldots \ldots \ldots \ldots \ldots \ldots \ldots . . \ldots \ldots \ldots$

$\mathrm{EC}_{50}$ values of compounds with regression equation............................. $4-5$

Copies of ${ }^{1} \mathrm{H}$ NMR, ${ }^{13} \mathrm{C}$ NMR and ${ }^{19} \mathrm{~F}$ NMR of compounds 5 \& 7 ...............6-30 


\section{Crystal data and structure refinement for compounds $7 \mathrm{e} \&$ \&}

Table S1. Crystal data and structure refinement for compound $7 \mathrm{e}$.

\begin{tabular}{|c|c|}
\hline Compounds & $7 e$ \\
\hline Empirical formula & $\mathrm{C}_{12} \mathrm{H}_{4} \mathrm{Cl}_{3} \mathrm{NO}_{3} \mathrm{~S}$ \\
\hline Formula weight & 348.57 \\
\hline Temperature/K & 113.15 \\
\hline Crystal system & orthorhombic \\
\hline Space group & Pbcn \\
\hline $\mathrm{a} / \AA$ & $9.1376(3)$ \\
\hline $\mathrm{b} / \AA$ & $21.8805(6)$ \\
\hline $\mathrm{c} / \AA$ & $13.4098(5)$ \\
\hline$\alpha /{ }^{\circ}$ & 90 \\
\hline$\beta /{ }^{\circ}$ & 90 \\
\hline$\gamma /{ }^{\circ}$ & 90 \\
\hline Volume $/ \AA^{3}$ & $2681.09(15)$ \\
\hline $\mathrm{Z}$ & 8 \\
\hline$\rho_{\text {calc }} \mathrm{g} / \mathrm{cm}^{3}$ & 1.727 \\
\hline$\mu / \mathrm{mm}^{-1}$ & 0.843 \\
\hline $\mathrm{F}(000)$ & 1392.0 \\
\hline Crystal size $/ \mathrm{mm}^{3}$ & $0.22 \times 0.2 \times 0.17$ \\
\hline Radiation & $\operatorname{MoK} \alpha(\lambda=0.71073)$ \\
\hline $2 \Theta$ range for data collection ${ }^{\circ}$ & 3.722 to 65.916 \\
\hline Index ranges & $-13 \leq \mathrm{h} \leq 13,-31 \leq \mathrm{k} \leq 32,-19 \leq 1 \leq 20$ \\
\hline Reflections collected & 38471 \\
\hline Independent reflections & $4796\left[R_{\text {int }}=0.0516, R_{\text {sigma }}=0.0295\right]$ \\
\hline Data/restraints/parameters & $4796 / 0 / 183$ \\
\hline Goodness-of-fit on $\mathrm{F}^{2}$ & 1.191 \\
\hline Final $R$ indexes $[I \geq 2 \sigma(I)]$ & $\mathrm{R}_{1}=0.0758, \mathrm{wR}_{2}=0.1672$ \\
\hline Final $\mathrm{R}$ indexes [all data] & $\mathrm{R}_{1}=0.0873, \mathrm{wR}_{2}=0.1723$ \\
\hline Largest diff. peak/hole / e $\AA^{-3}$ & $1.69 /-0.80$ \\
\hline
\end{tabular}


Table S2. Crystal data and structure refinement for compound 7r.

\begin{tabular}{|c|c|}
\hline Compounds & $7 r$ \\
\hline Empirical formula & $\mathrm{C}_{13} \mathrm{H}_{6} \mathrm{Cl}_{2} \mathrm{FNO}_{3} \mathrm{~S}$ \\
\hline Formula weight & 346.15 \\
\hline Temperature/K & 113.15 \\
\hline Crystal system & monoclinic \\
\hline Space group & $\mathrm{P} 2{ }_{1} / \mathrm{c}$ \\
\hline $\mathrm{a} / \AA$ & $11.5617(4)$ \\
\hline $\mathrm{b} / \AA$ & $8.7861(2)$ \\
\hline $\mathrm{c} / \AA$ & $13.9775(4)$ \\
\hline$\alpha /^{\circ}$ & 90 \\
\hline$\beta /^{\circ}$ & $112.834(4)$ \\
\hline$\gamma /{ }^{\circ}$ & 90 \\
\hline Volume $/ \AA^{3}$ & $1308.59(7)$ \\
\hline $\mathrm{Z}$ & 4 \\
\hline$\rho_{\text {calcg }} / \mathrm{cm}^{3}$ & 1.757 \\
\hline$\mu / \mathrm{mm}^{-1}$ & 0.675 \\
\hline $\mathrm{F}(000)$ & 696.0 \\
\hline Crystal size $/ \mathrm{mm}^{3}$ & $0.22 \times 0.2 \times 0.17$ \\
\hline Radiation & $\operatorname{MoK} \alpha(\lambda=0.71073)$ \\
\hline $2 \Theta$ range for data collection ${ }^{\circ}$ & 3.822 to 65.834 \\
\hline Index ranges & $-17 \leq \mathrm{h} \leq 16,-13 \leq \mathrm{k} \leq 12,-20 \leq 1 \leq 18$ \\
\hline Reflections collected & 18982 \\
\hline Independent reflections & $4526\left[R_{\text {int }}=0.0447, R_{\text {sigma }}=0.0287\right]$ \\
\hline Data/restraints/parameters & $4526 / 0 / 193$ \\
\hline Goodness-of-fit on $\mathrm{F}^{2}$ & 1.051 \\
\hline Final $R$ indexes $[I \geq 2 \sigma(I)]$ & $\mathrm{R}_{1}=0.0315, \mathrm{wR}_{2}=0.0817$ \\
\hline Final $\mathrm{R}$ indexes [all data] & $\mathrm{R}_{1}=0.0356, \mathrm{wR}_{2}=0.0851$ \\
\hline Largest diff. peak/hole / e $\AA^{-3}$ & $0.49 /-0.43$ \\
\hline
\end{tabular}




\section{$\mathrm{EC}_{50}$ values of compounds with regression equation}

Table S3. EC $_{50}$ Values of compounds with inhibition over $85 \%$ at $25 \mu \mathrm{g} / \mathrm{mL}$

\begin{tabular}{|c|c|c|c|c|}
\hline Fungi & Cmpd. & Regression equation & $\mathrm{R}^{2}$ & $\mathrm{EC}_{50}(\mu \mathrm{g} / \mathrm{mL})$ \\
\hline \multirow[t]{16}{*}{ R. $s$} & $7 \mathbf{a}$ & $y=3.9677+1.5295 x$ & 0.9838 & 4.73 \\
\hline & $7 b$ & $y=3.9626+1.3553 x$ & 0.9966 & 5.83 \\
\hline & 7c & $y=5.0639+0.8947 x$ & 0.9988 & 0.85 \\
\hline & $7 e$ & $y=4.4109+1.3101 x$ & 0.9819 & 0.98 \\
\hline & $7 f$ & $y=4.9015+0.8013 x$ & 0.9858 & 1.33 \\
\hline & $7 \mathrm{~g}$ & $y=4.7327+1.1261 x$ & 0.9818 & 1.73 \\
\hline & $7 \mathbf{h}$ & $y=4.5925+1.0804 x$ & 0.9939 & 2.38 \\
\hline & $7 \mathbf{i}$ & $y=4.0303+1.1478 x$ & 0.9529 & 7.00 \\
\hline & $7 \mathbf{j}$ & $y=4.5407+1.8631 x$ & 0.9961 & 1.76 \\
\hline & $7 \mathbf{k}$ & $y=6.1068+1.8102 x$ & 0.9631 & 0.24 \\
\hline & $7 \mathrm{~m}$ & $y=4.0561+1.0100 x$ & 0.9917 & 8.60 \\
\hline & $7 n$ & $y=4.5307+1.1402 x$ & 0.9945 & 2.58 \\
\hline & $7 p$ & $y=3.9647+1.0887 x$ & 0.9854 & 8.93 \\
\hline & $7 r$ & $y=3.5690+1.4523 x$ & 0.9769 & 9.67 \\
\hline & osthole & $y=3.7903+1.3147 x$ & 0.9948 & 8.32 \\
\hline & azoxystrobin & $y=5.6707+1.3403 x$ & 0.9668 & 0.32 \\
\hline \multirow[t]{12}{*}{ P. $p$} & $7 b$ & $y=3.9657+1.3588 x$ & 0.9018 & 5.77 \\
\hline & 7c & $y=4.8450+1.5483 x$ & 0.9941 & 1.26 \\
\hline & $7 e$ & $y=3.5803+1.8973 x$ & 0.9229 & 5.60 \\
\hline & $7 f$ & $y=4.2839+0.7369 x$ & 0.9691 & 9.37 \\
\hline & $7 g$ & $y=4.8852+0.8343 x$ & 0.9936 & 1.37 \\
\hline & $7 \mathbf{h}$ & $y=4.1181+1.5518 x$ & 0.9807 & 3.70 \\
\hline & 71 & $y=4.0093+1.4791 x$ & 0.9776 & 4.67 \\
\hline & 70 & $y=3.9711+1.5167 x$ & 0.9510 & 4.77 \\
\hline & $7 p$ & $y=3.7626+1.7058 x$ & 0.9485 & 5.31 \\
\hline & $7 r$ & $y=4.3807+1.7082 x$ & 0.9859 & 2.30 \\
\hline & osthole & $y=0.5260+2.3891 x$ & 0.9727 & 74.59 \\
\hline & azoxystrobin $^{1}$ & $y=4.7465+0.2720 x$ & 0.9896 & 14.48 \\
\hline \multirow[t]{7}{*}{ S. $s$} & $7 \mathrm{~g}$ & $y=4.4756+1.3179 x$ & 0.9608 & 2.50 \\
\hline & $7 \mathbf{j}$ & $y=3.7459+1.5740 x$ & 0.9434 & 6.26 \\
\hline & 71 & $y=4.4838+1.0985 x$ & 0.9260 & 2.95 \\
\hline & 70 & $y=4.2925+1.1787 x$ & 0.9941 & 3.98 \\
\hline & $7 r$ & $y=4.6004+0.8726 x$ & 0.9983 & 2.87 \\
\hline & osthole & $y=2.8079+1.3590 x$ & 0.9264 & 41.03 \\
\hline & azoxystrobin $^{l}$ & $y=4.6795+0.5283 x$ & 0.8375 & 4.04 \\
\hline \multirow[t]{4}{*}{ B. $c$} & $7 e$ & $y=4.2813+1.5311 x$ & 0.9923 & 2.95 \\
\hline & $7 g$ & $y=5.0635+1.1778 x$ & 0.9857 & 0.88 \\
\hline & $7 \mathbf{h}$ & $y=4.4575+1.0380 x$ & 0.9956 & 3.33 \\
\hline & $7 \mathbf{i}$ & $y=4.1411+1.5409 x$ & 0.9762 & 3.60 \\
\hline
\end{tabular}




\begin{tabular}{cccc}
\hline $\mathbf{7 1}$ & $y=4.3915+1.1787 x$ & 0.9500 & 3.02 \\
$\mathbf{7 n}$ & $y=4.5803+0.9115 x$ & 0.9971 & 2.89 \\
$\mathbf{7 p}$ & $y=4.4674+1.0227 x$ & 0.9958 & 3.31 \\
osthole $^{1}$ & $y=3.5371+1.6848 x$ & 0.9899 & 7.38 \\
azoxystrobin $^{l}$ & $y=4.1911+0.6860 x$ & 0.9549 & 15.11 \\
\hline
\end{tabular}

B. c, Botrytis cinerea; P. p, Physalospora piricola; R. s, Rhizoctonia solani; S. s, Sclerotinia sclerotiorum. Data were cited in ref 1 for comparison, all data were determined under the same conditions.

\section{Reference:}

1. Chen, L.; Zhao, B.; Fan, Z. J.; Liu, X. M.; Wu, Q. F.; Li, H. P.; Wang, H. X., Synthesis of novel 3,4-chloroisothiazole-based imidazoles as fungicides and evaluation of their mode of action. J. Agric. Food Chem. 2018, 66, 7319-7327. 
Copies of ${ }^{1} \mathrm{H}$ NMR, ${ }^{13} \mathrm{C}$ NMR and ${ }^{19}$ F NMR of compounds $5 \& 7$

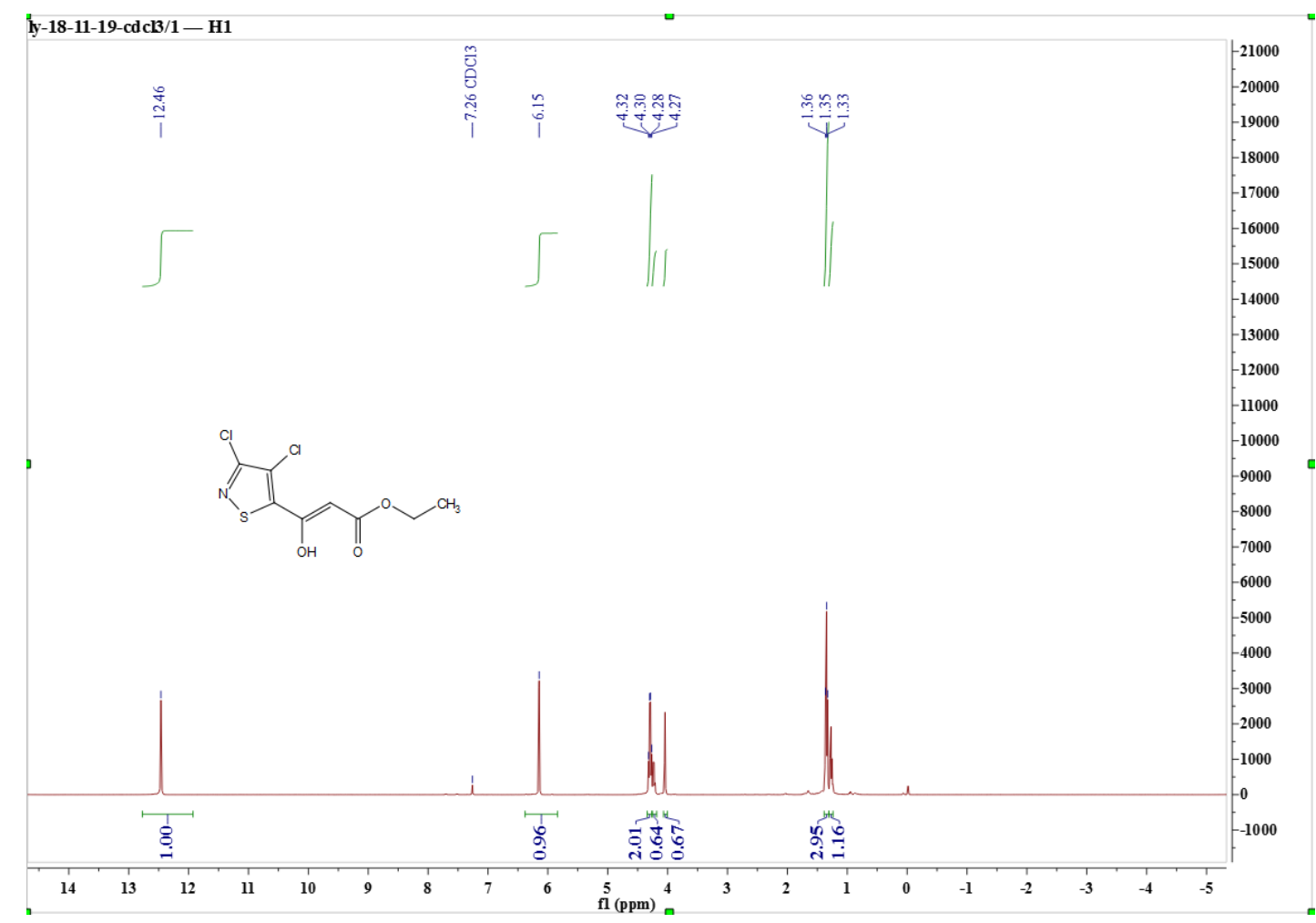

Figure S1. The ${ }^{1} \mathrm{H}$ NMR (400 MHz, $\left.\mathrm{CDCl}_{3}\right)$ of compound $\mathbf{5 a}$.

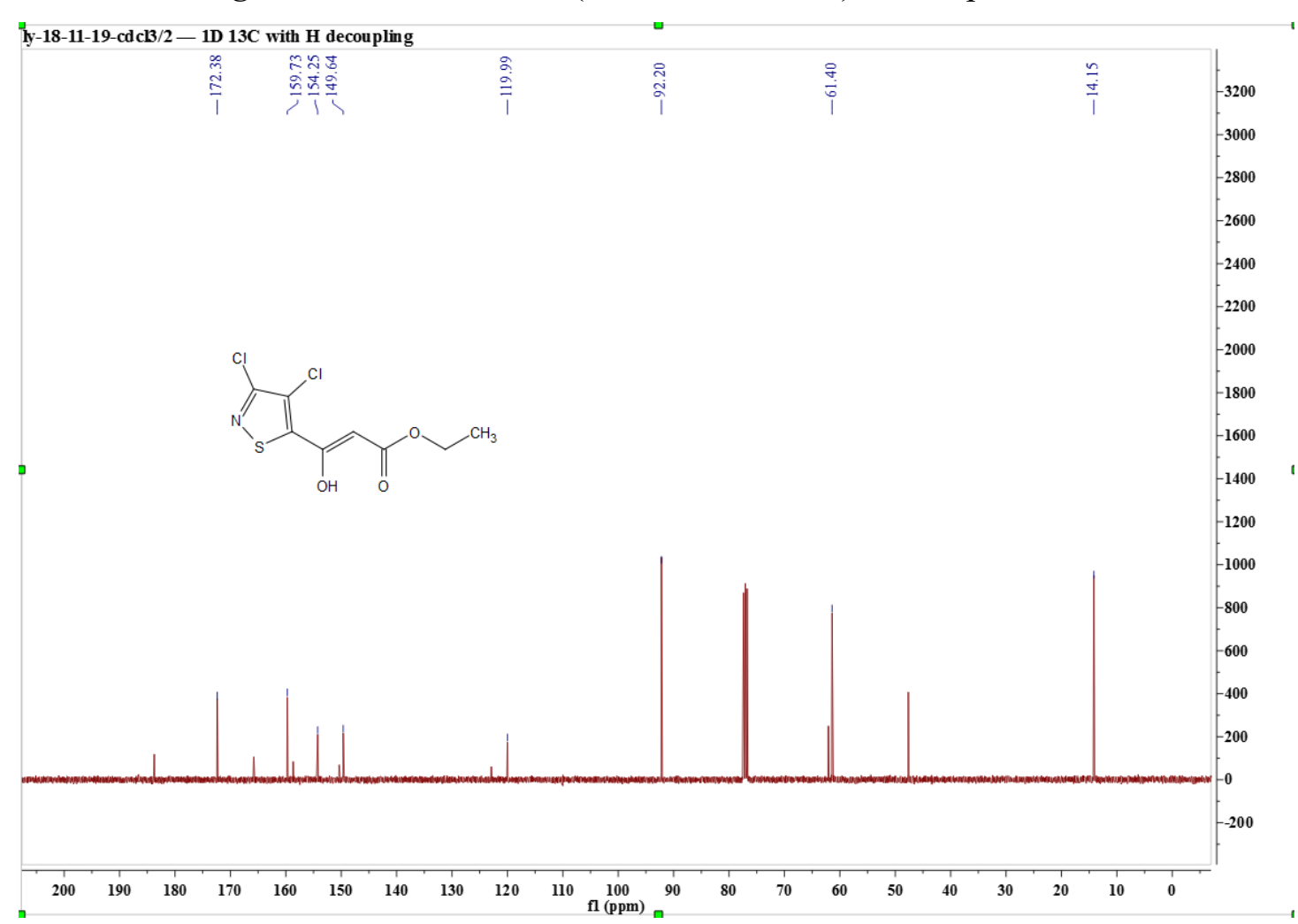

Figure $S 2$. The ${ }^{13} \mathrm{C}$ NMR (101 MHz, $\left.\mathrm{CDCl}_{3}\right)$ of compound 5 a. 


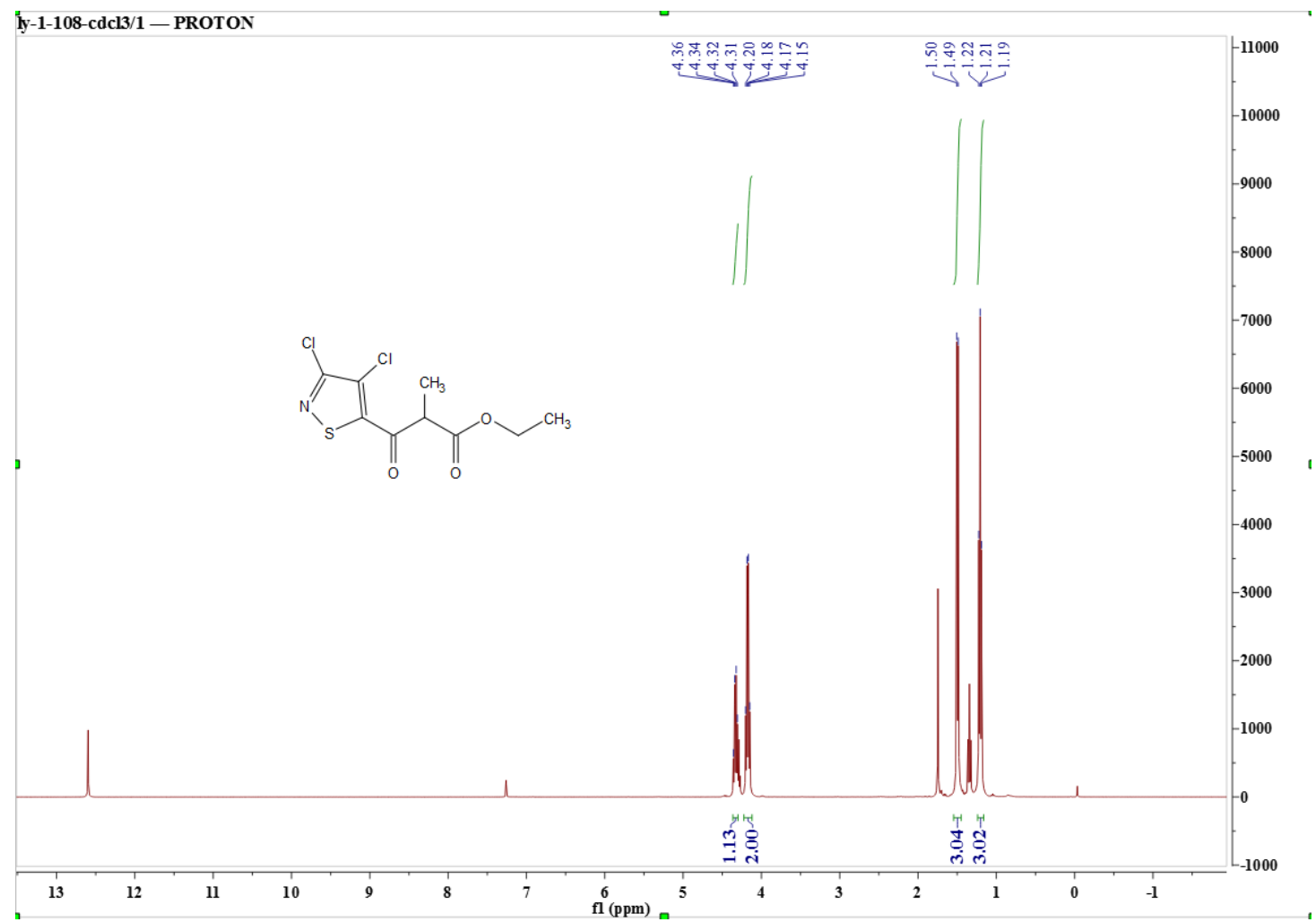

Figure $S 3$. The ${ }^{1} \mathrm{H}$ NMR (400 $\left.\mathrm{MHz}, \mathrm{CDCl}_{3}\right)$ of compound $\mathbf{5 b}$.

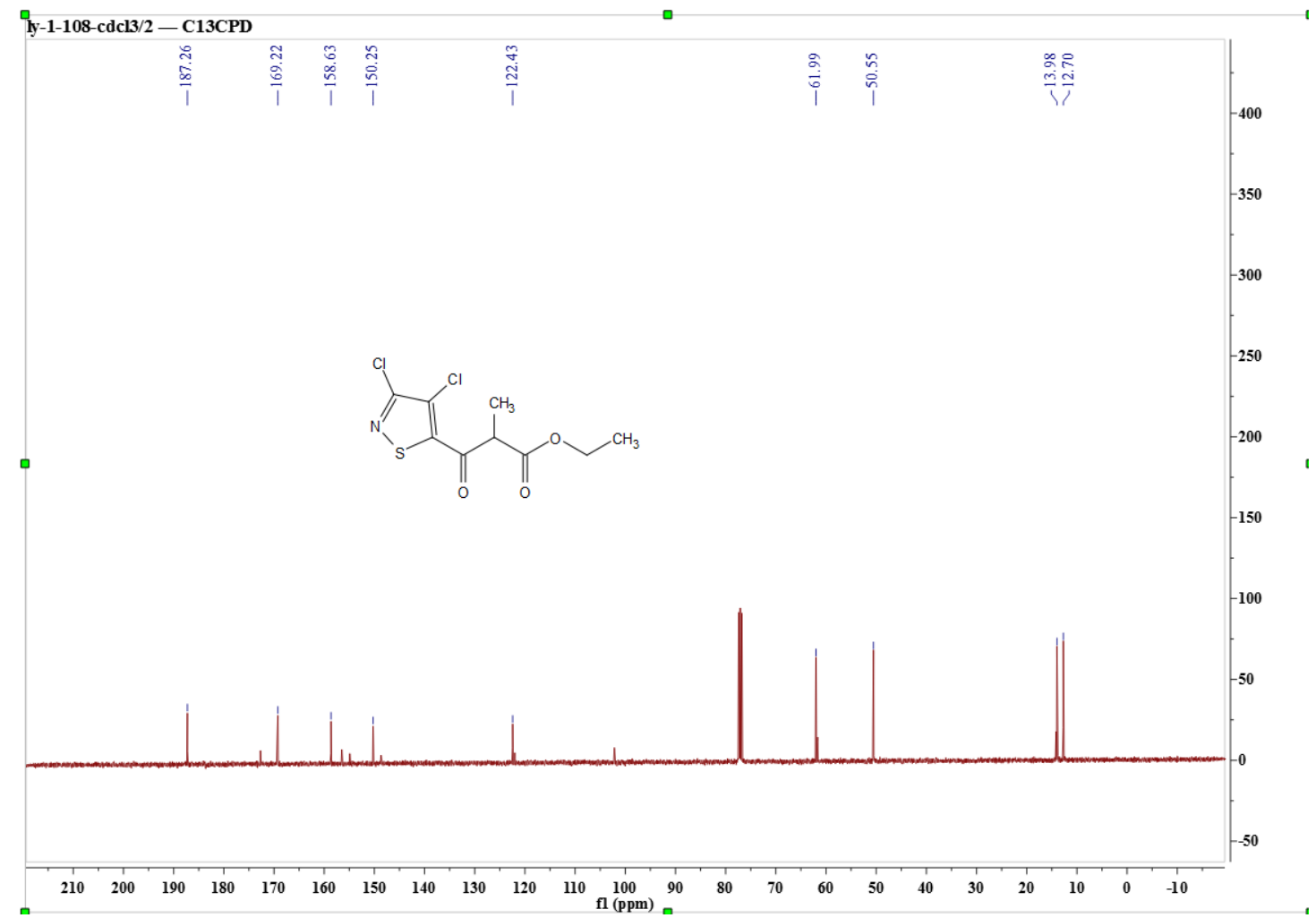

Figure 54 . The ${ }^{13} \mathrm{C}$ NMR $\left(101 \mathrm{MHz}, \mathrm{CDCl}_{3}\right)$ of compound $\mathbf{5 b}$. 


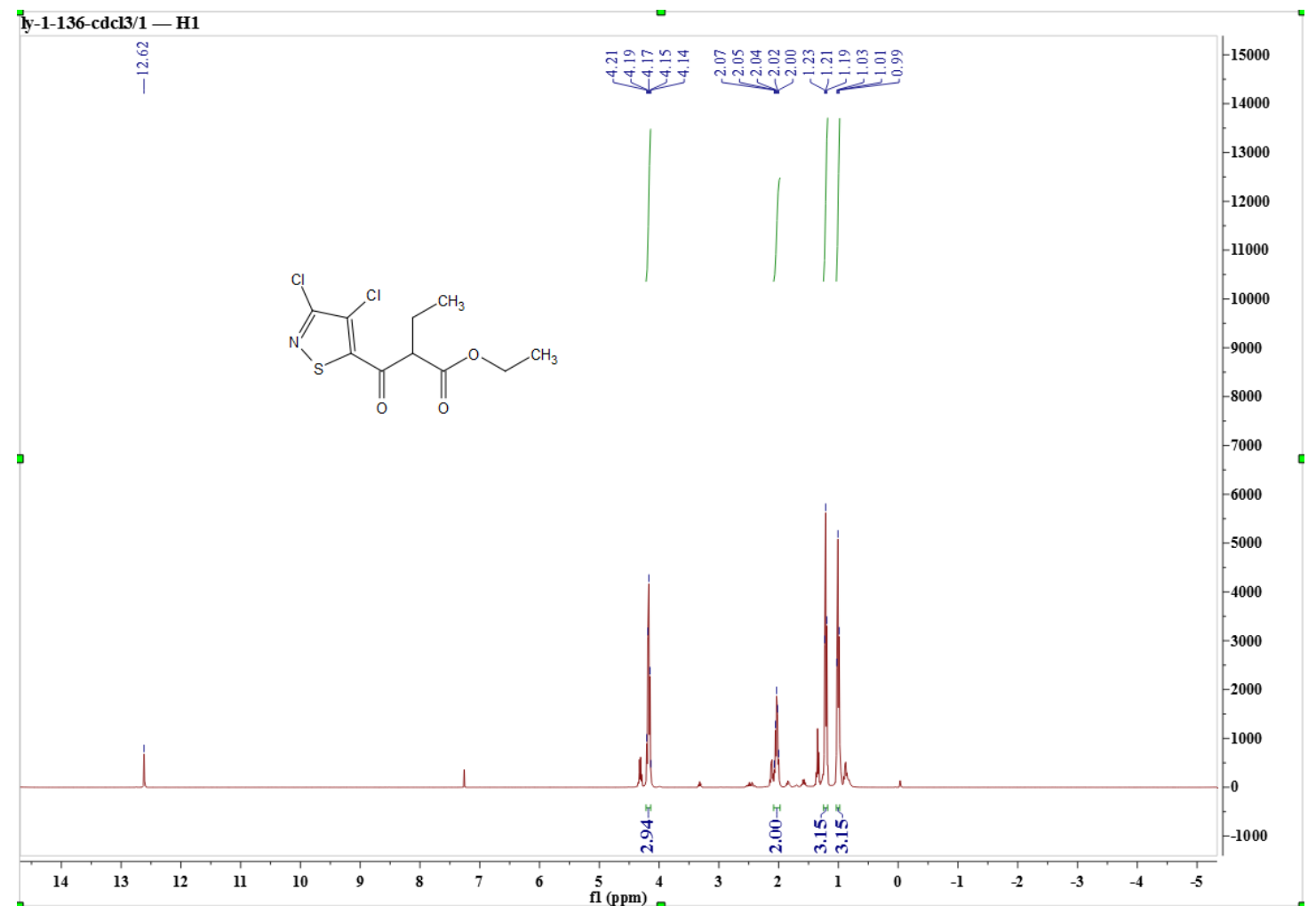

Figure S5. The ${ }^{1} \mathrm{H}$ NMR (400 MHz, $\left.\mathrm{CDCl}_{3}\right)$ of compound sc.

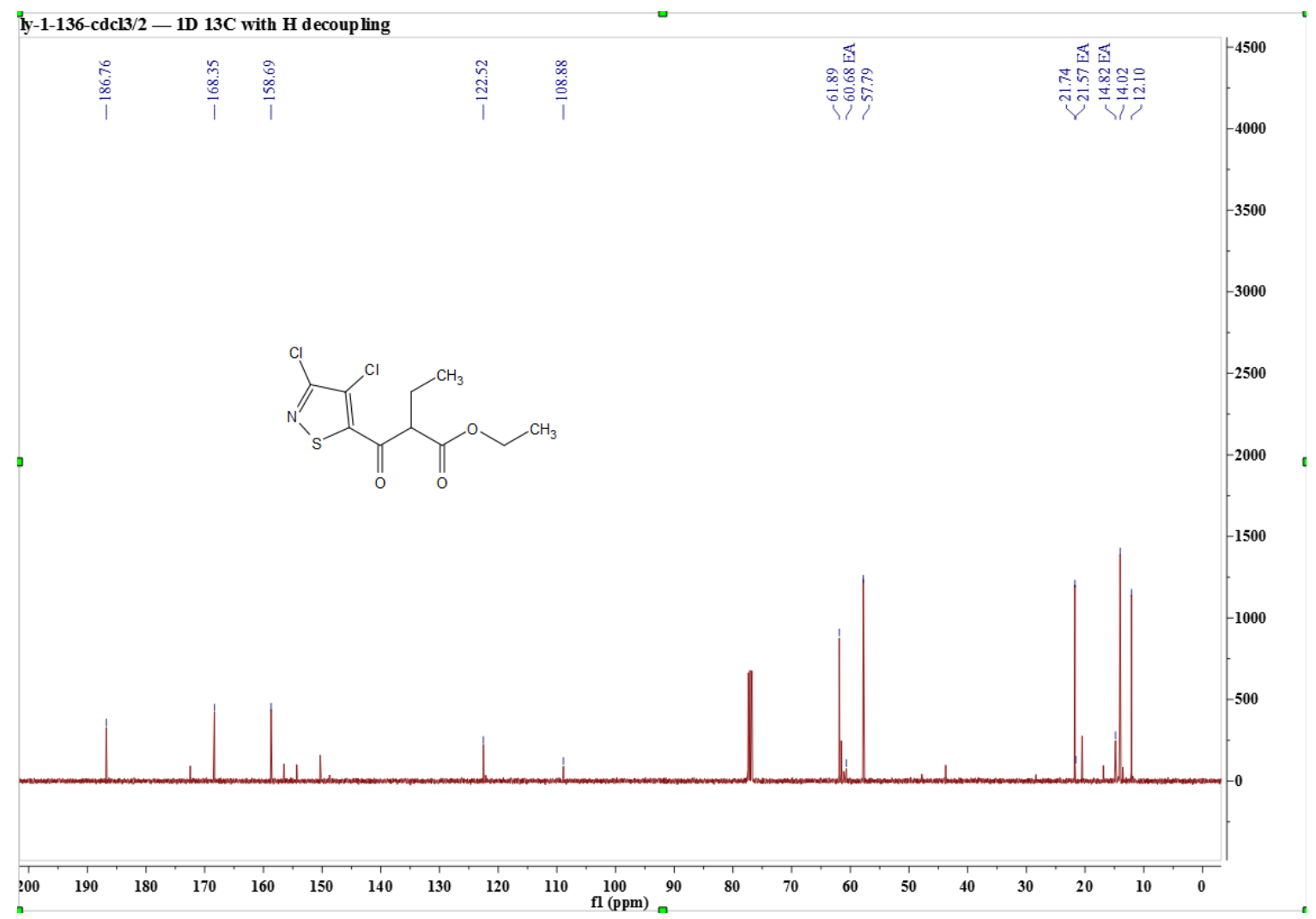

Figure S6. The ${ }^{13} \mathrm{C}$ NMR $\left(101 \mathrm{MHz}, \mathrm{CDCl}_{3}\right)$ of compound sc.

$8 / 30$ 


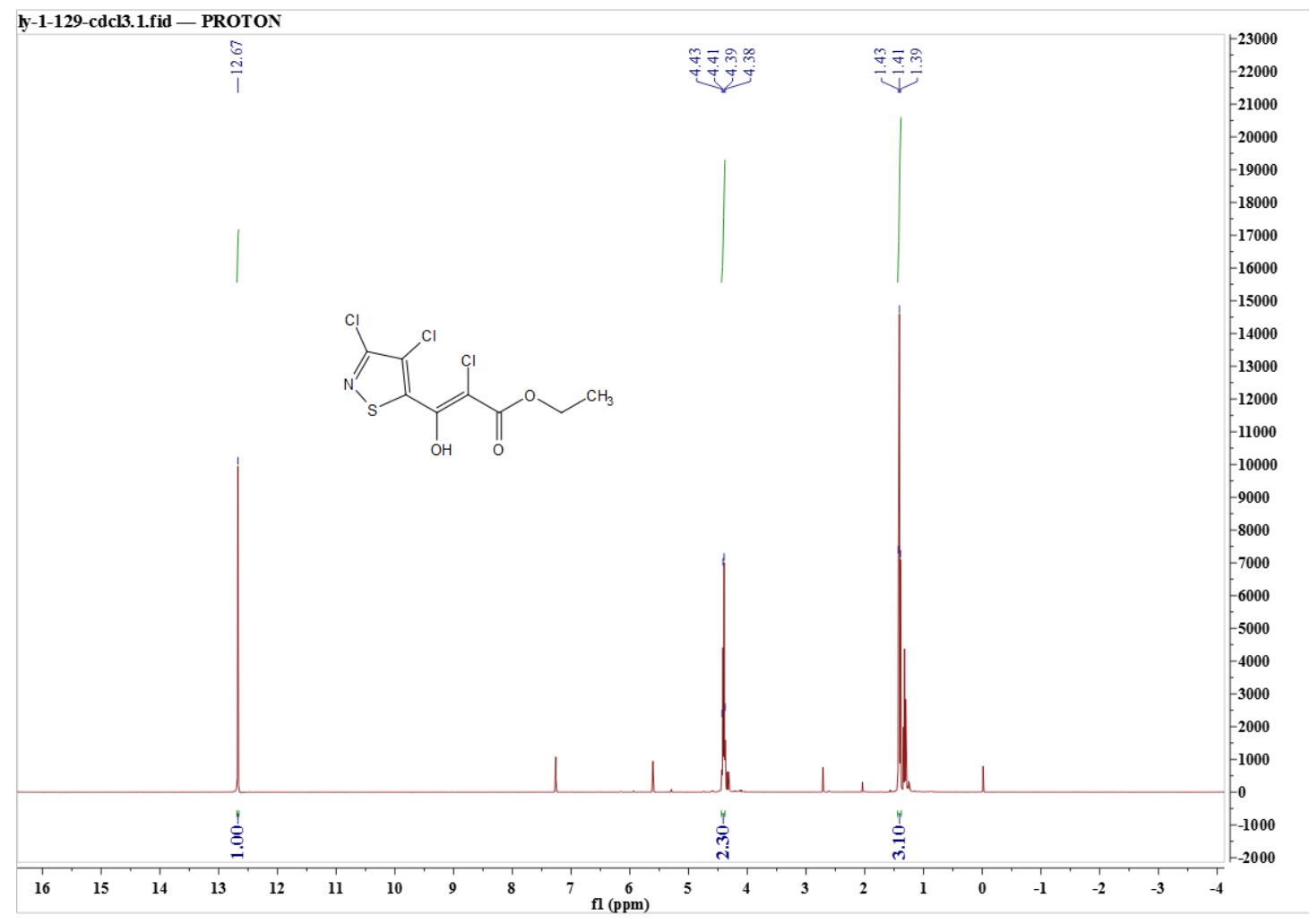

Figure $S 7$. The ${ }^{1} \mathrm{H}$ NMR (400 MHz, $\left.\mathrm{CDCl}_{3}\right)$ of compound $\mathbf{5 d}$.

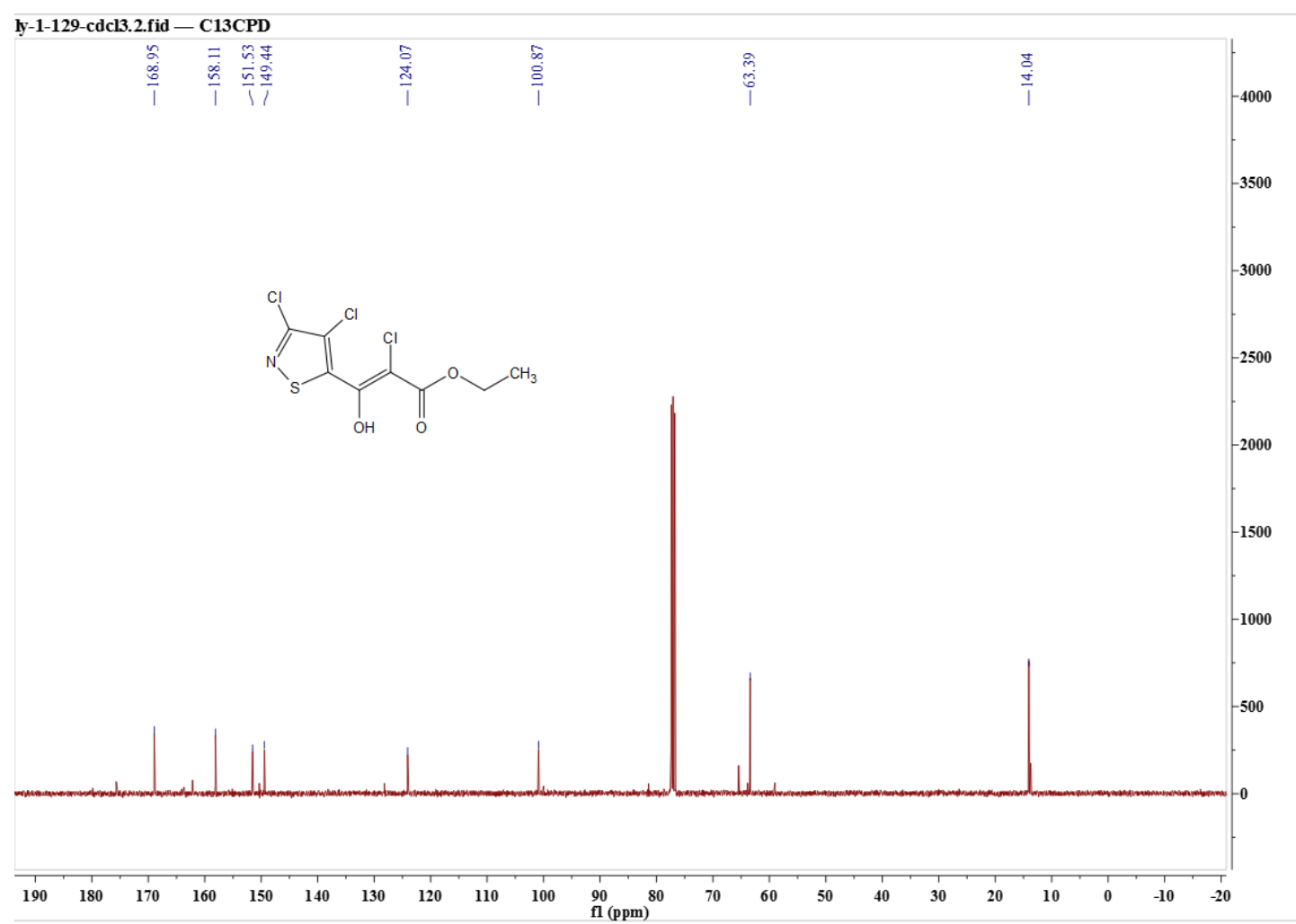

Figure S8. The ${ }^{13} \mathrm{C}$ NMR (101 MHz, $\left.\mathrm{CDCl}_{3}\right)$ of compound $\mathbf{5 d}$. 


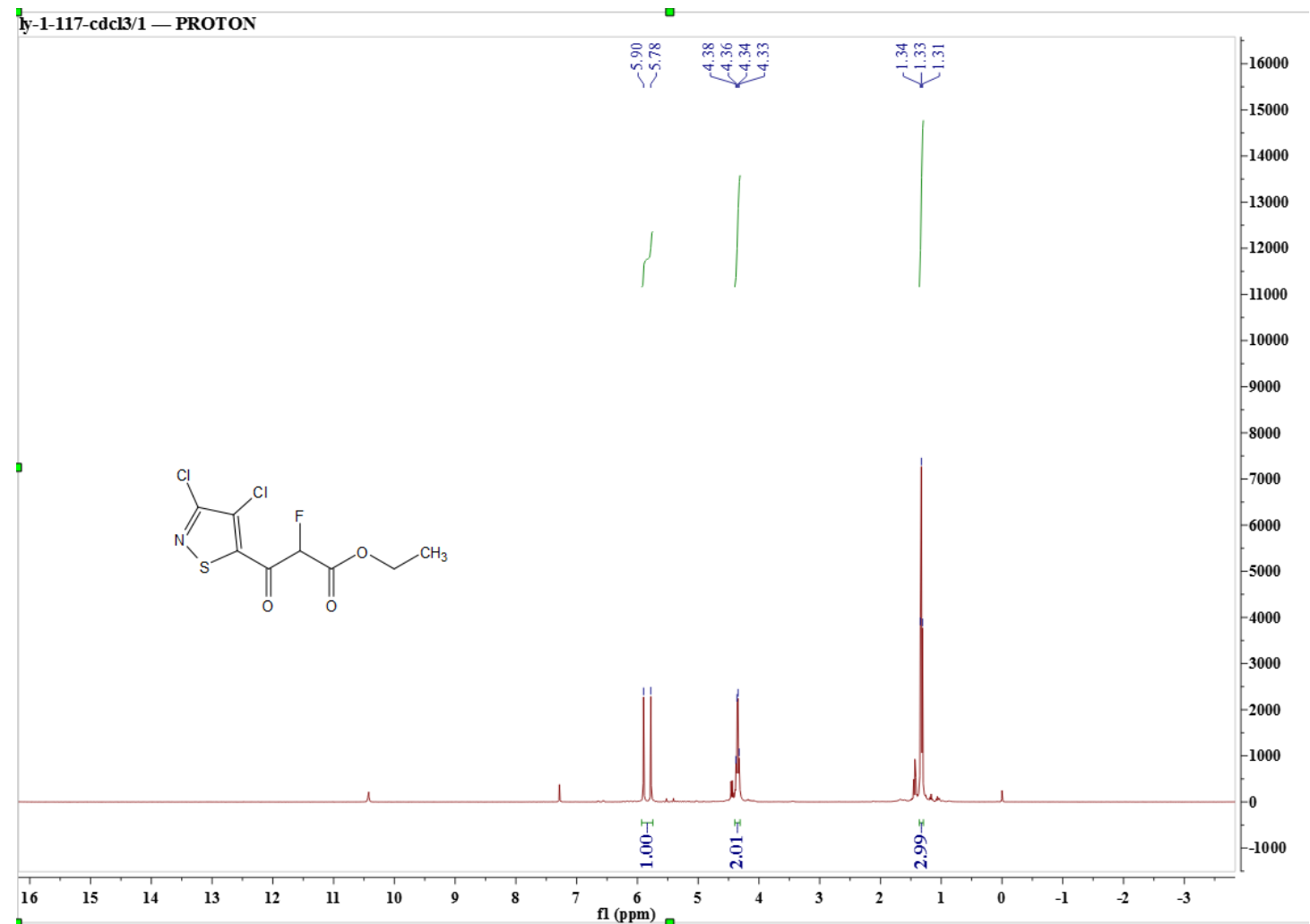

Figure S9. The ${ }^{1} \mathrm{H}$ NMR $\left(400 \mathrm{MHz}, \mathrm{CDCl}_{3}\right)$ of compound $5 \mathbf{e}$.

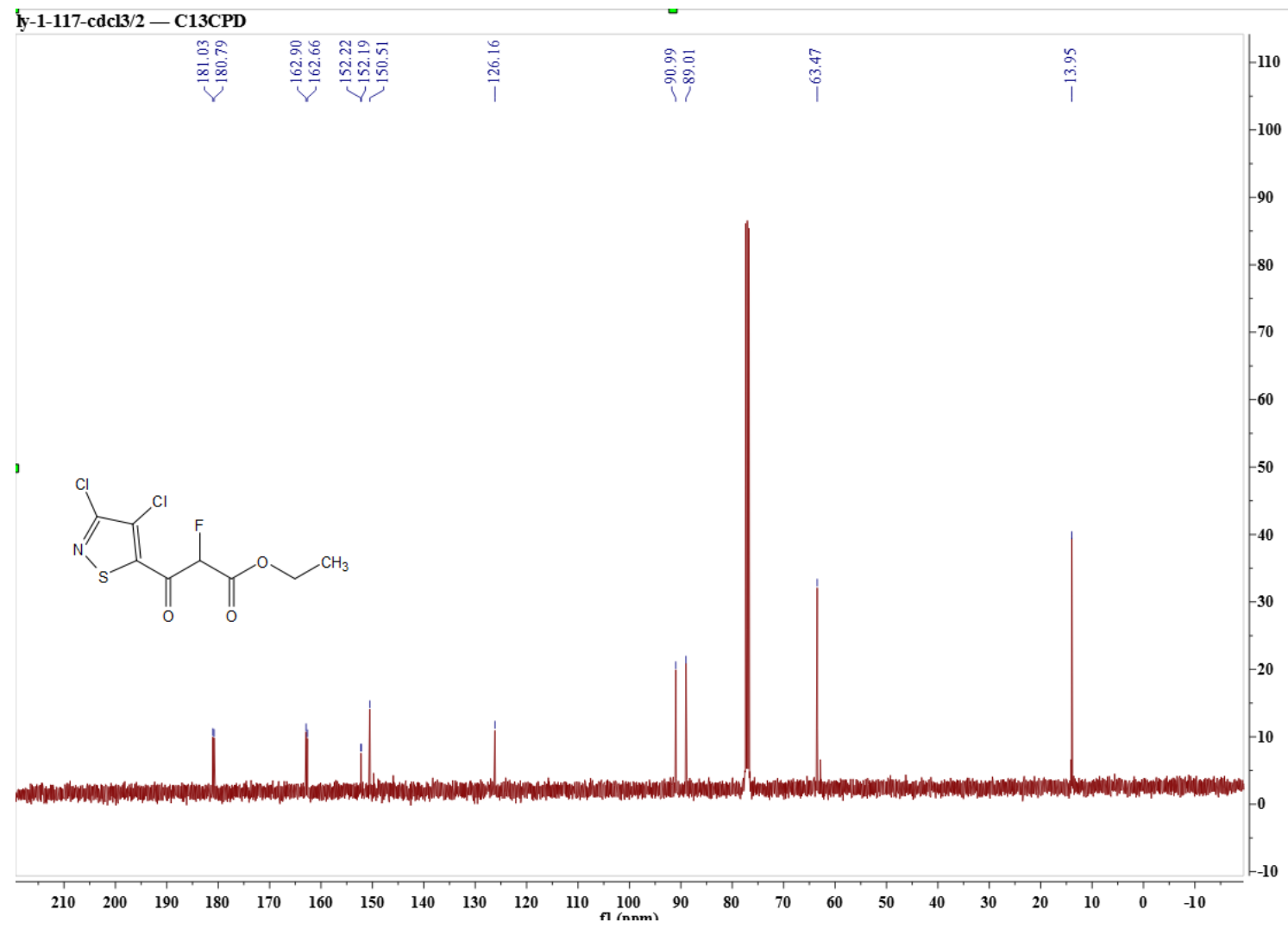

Figure S10. The ${ }^{13} \mathrm{C}$ NMR (101 MHz, $\left.\mathrm{CDCl}_{3}\right)$ of compound $5 \mathbf{e}$. 


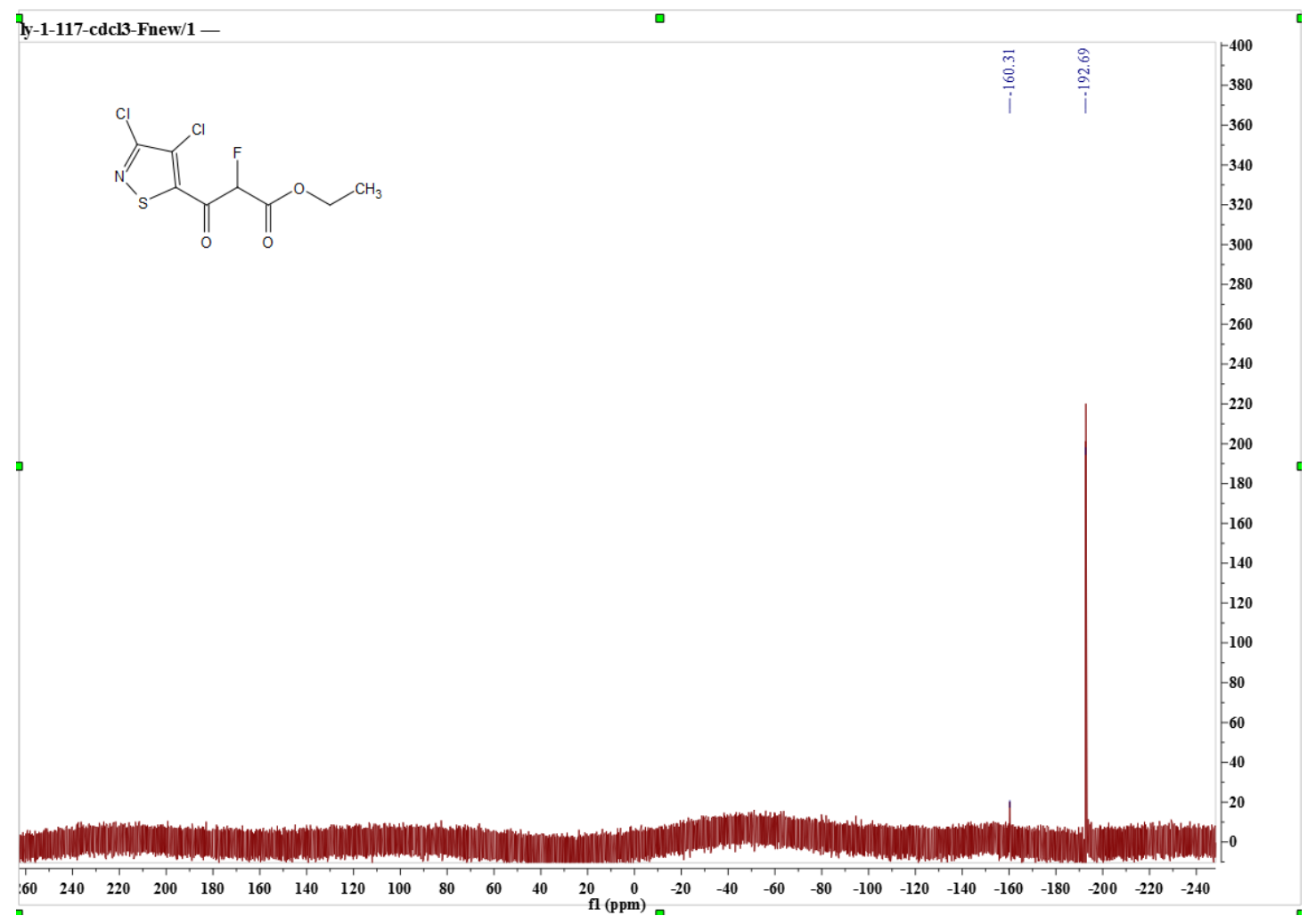

Figure S11. The ${ }^{19} \mathrm{~F}$ NMR (376 MHz, $\left.\mathrm{CDCl}_{3}\right)$ of compound $5 \mathbf{e}$.

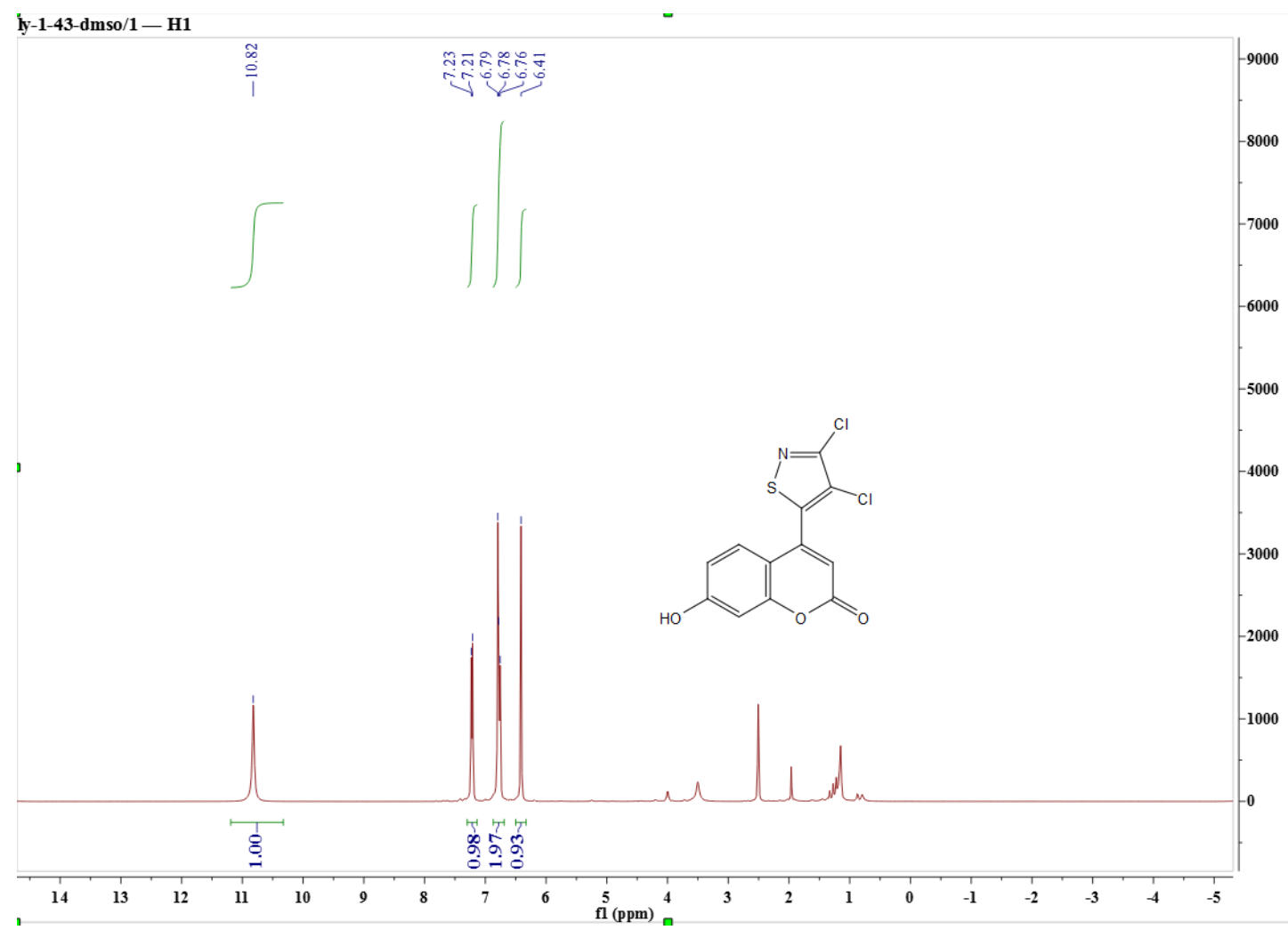

Figure S12. The ${ }^{1} \mathrm{H}$ NMR (400 MHz, DMSO- $d 6$ ) of compound 7a. 


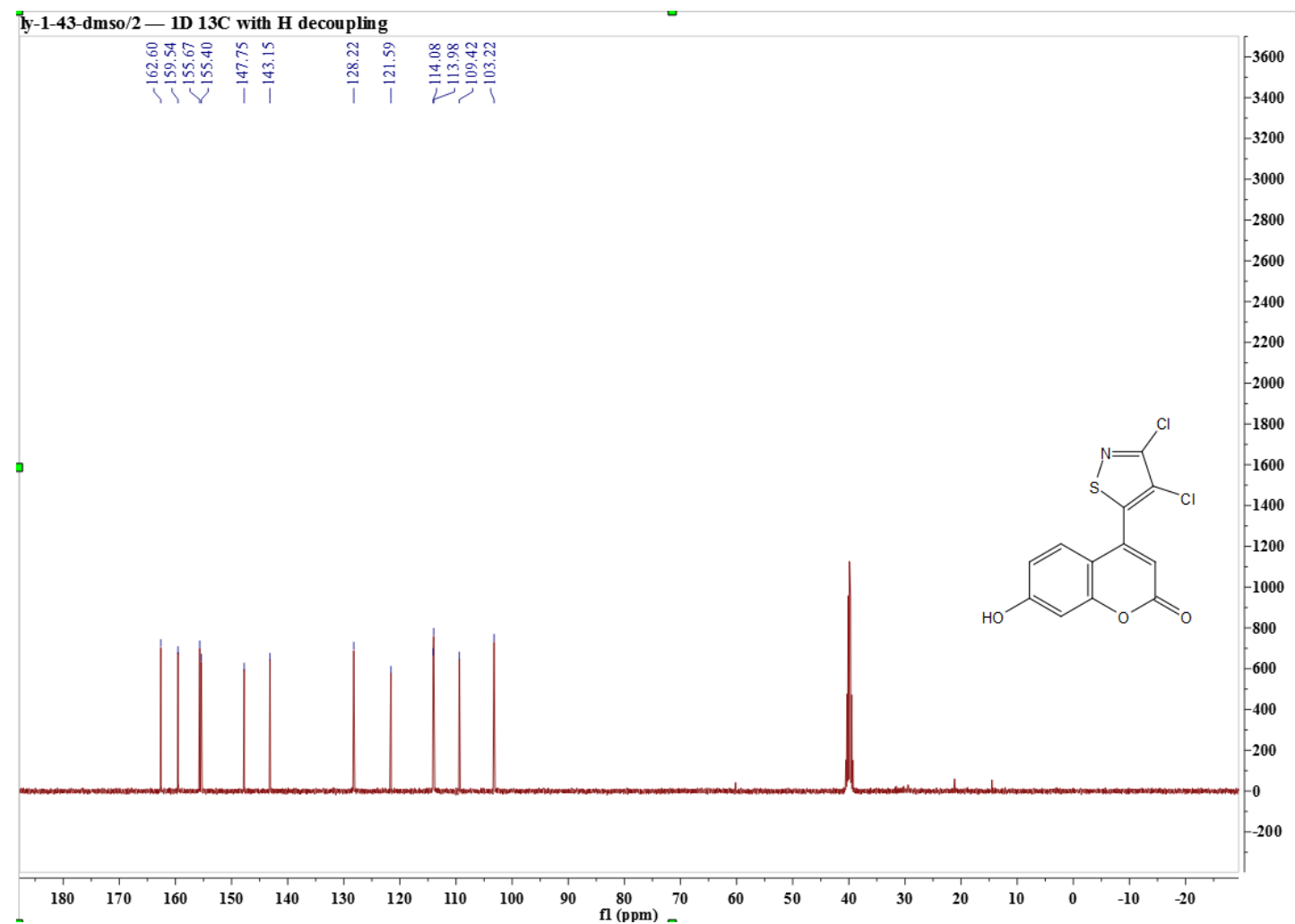

Figure S13. The ${ }^{13} \mathrm{C}$ NMR (101 MHz, DMSO-d6) of compound 7a.

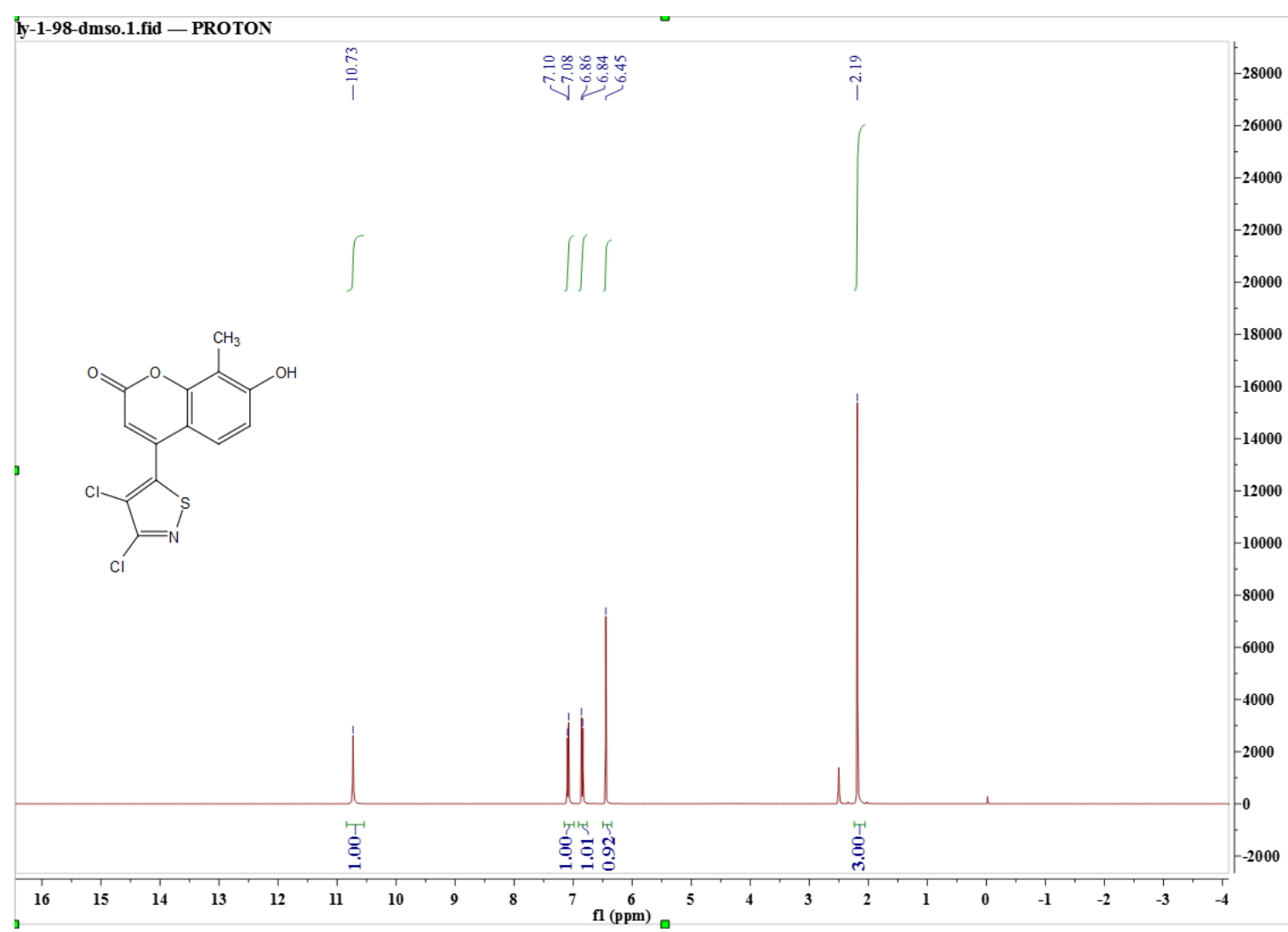

Figure S14. The ${ }^{1} \mathrm{H}$ NMR (400 MHz, DMSO-d6) of compound $7 \mathbf{b}$. 


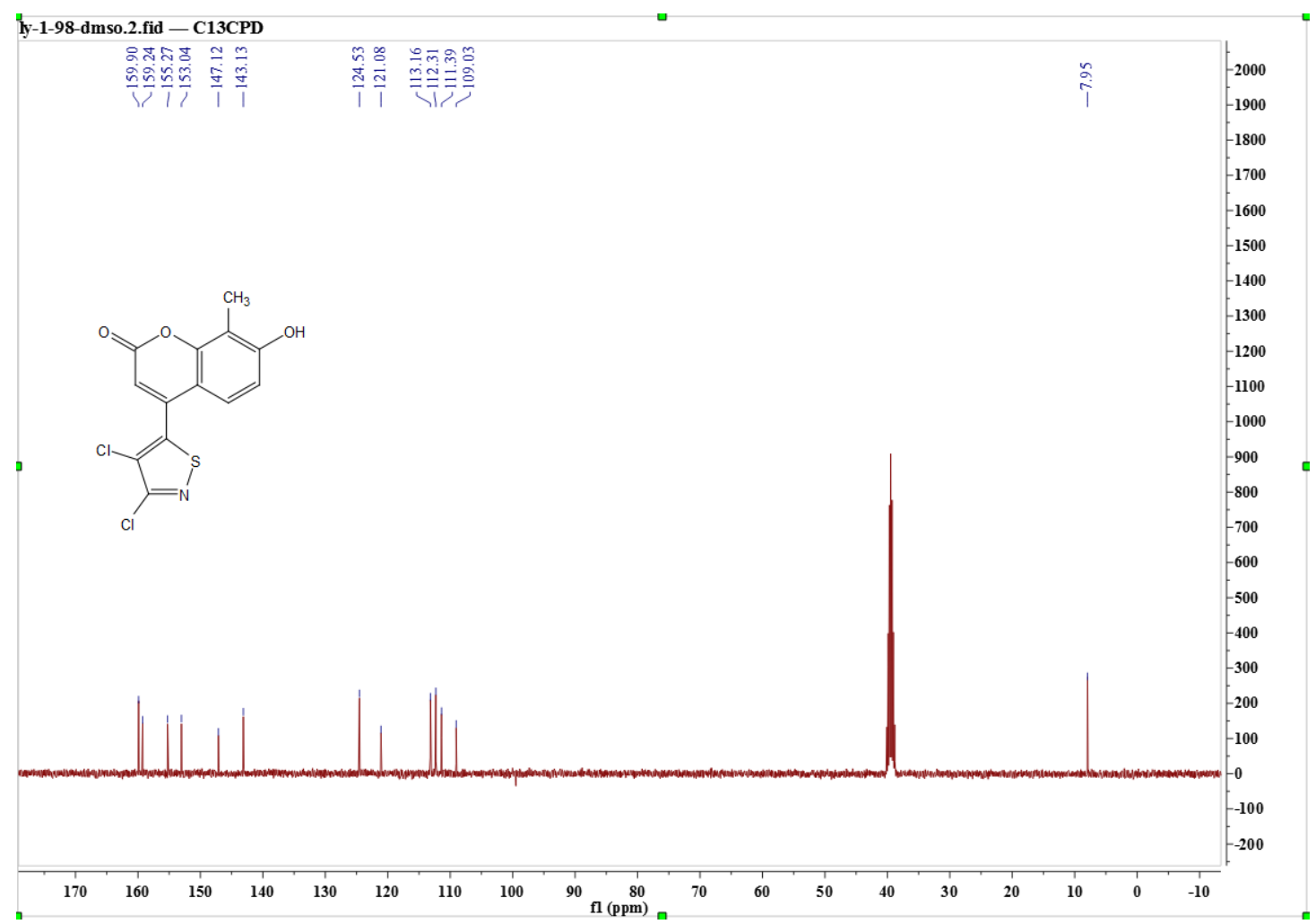

Figure S15. The ${ }^{13} \mathrm{C}$ NMR (101 MHz, DMSO-d6) of compound $7 \mathbf{b}$.

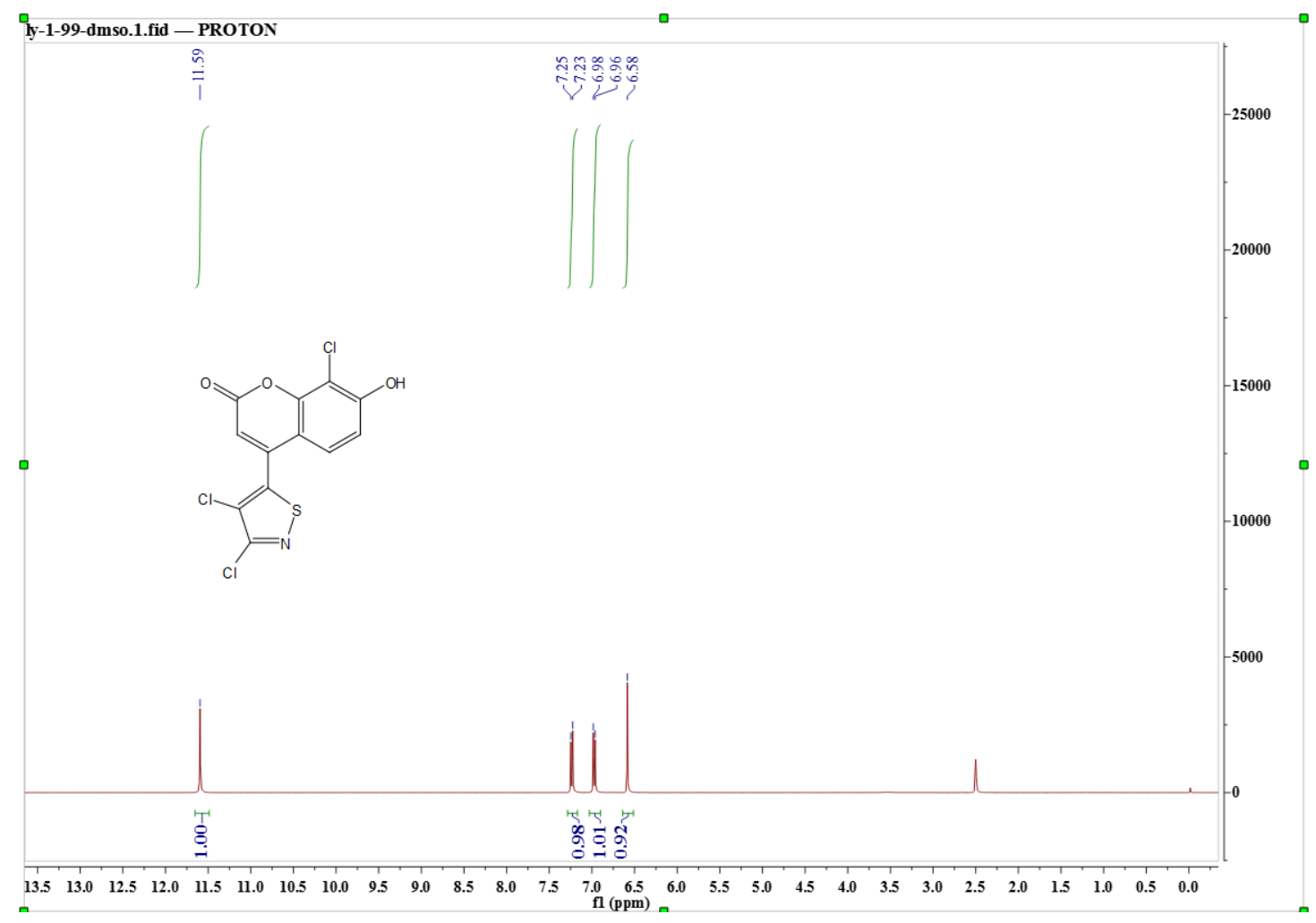

Figure S16. The ${ }^{1} \mathrm{H}$ NMR (400 MHz, DMSO-d6) of compound 7c. 


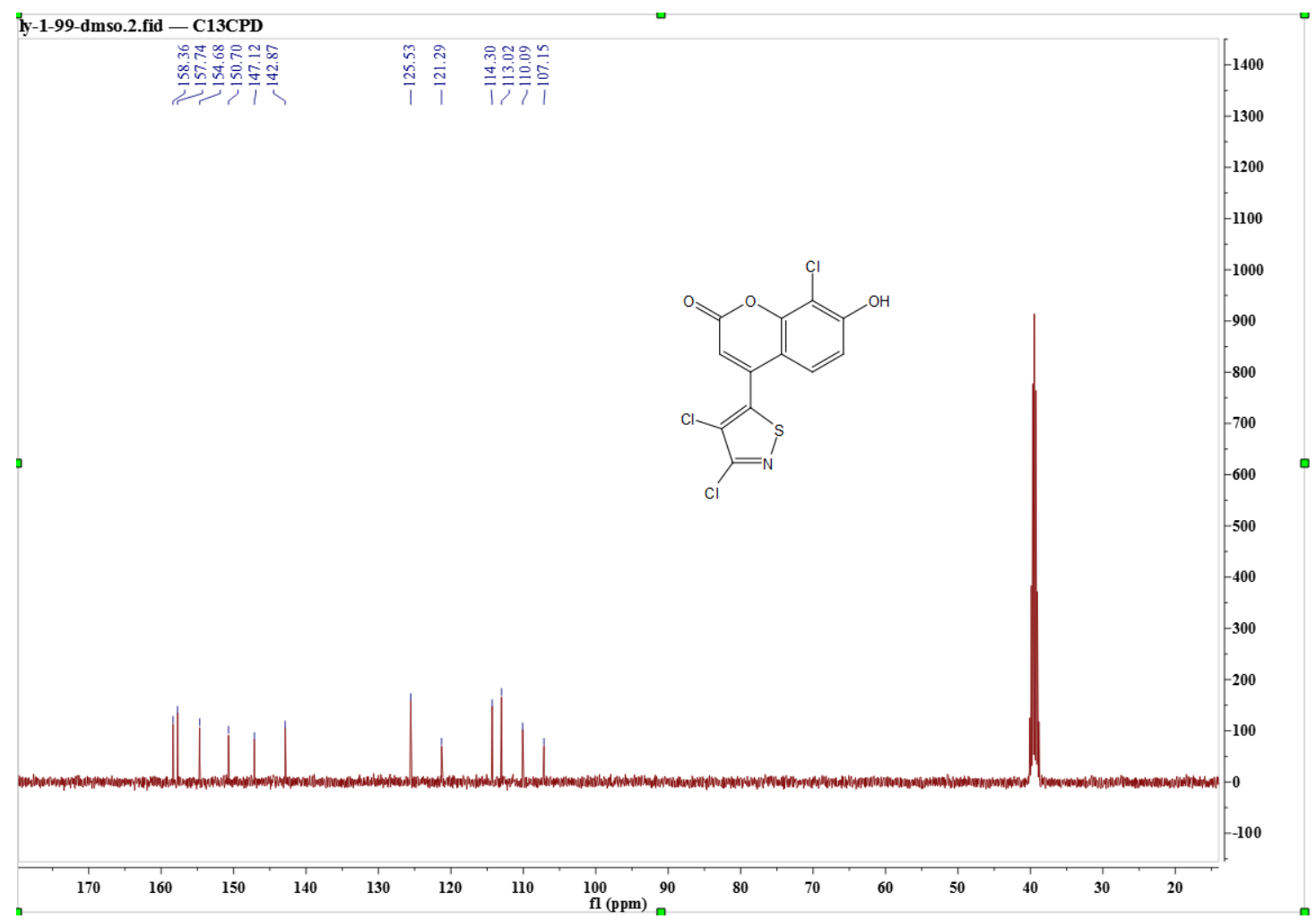

Figure S17. The ${ }^{13} \mathrm{C}$ NMR (101 MHz, DMSO-d6) of compound 7c.

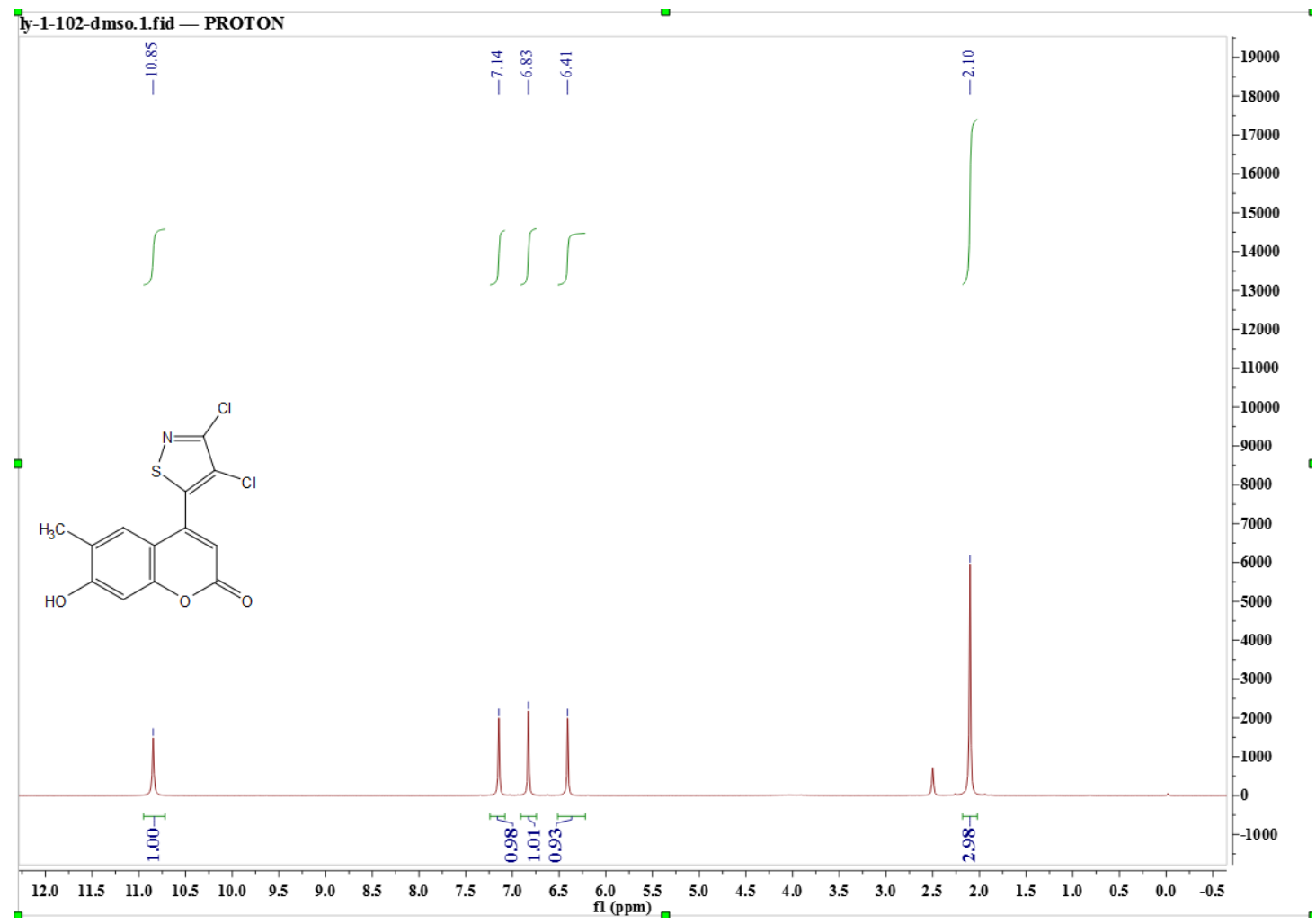

Figure S18. The ${ }^{1} \mathrm{H}$ NMR (400 MHz, DMSO-d6) of compound 7d. 


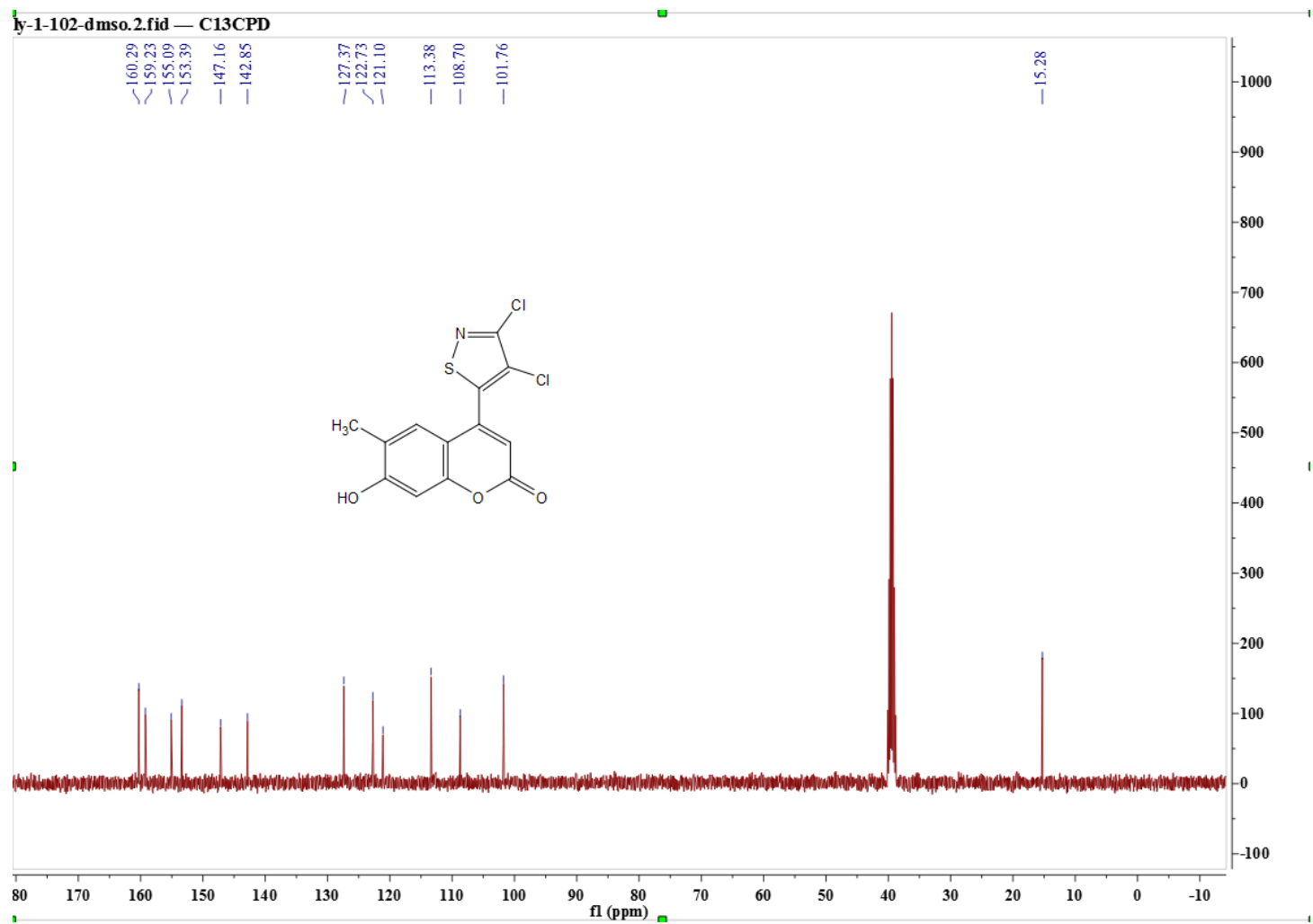

Figure S19. The ${ }^{13} \mathrm{C}$ NMR (101 MHz, DMSO-d6) of compound 7d.

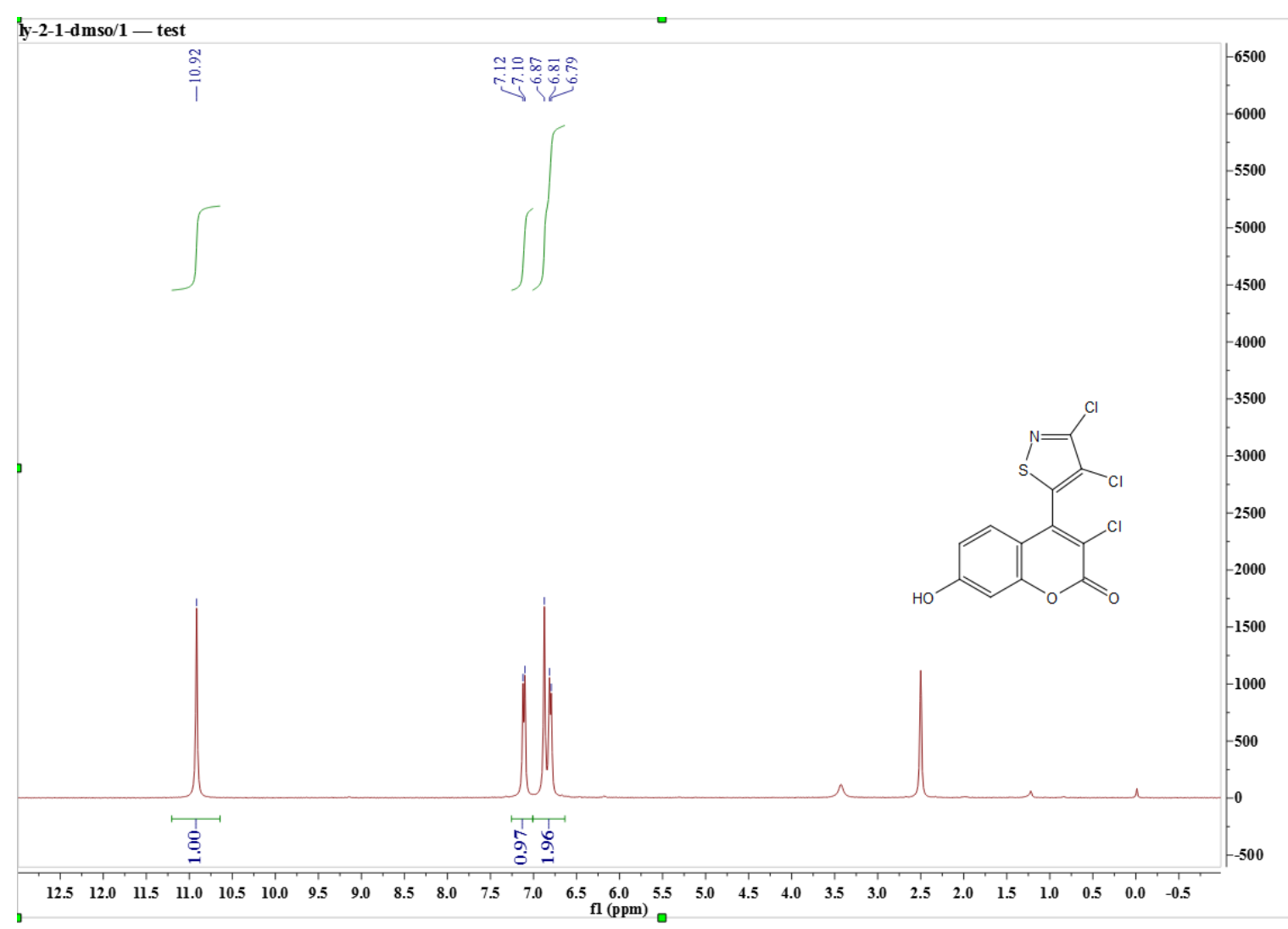

Figure S20. The ${ }^{1} \mathrm{H}$ NMR (400 MHz, DMSO- $d 6$ ) of compound 7e. 


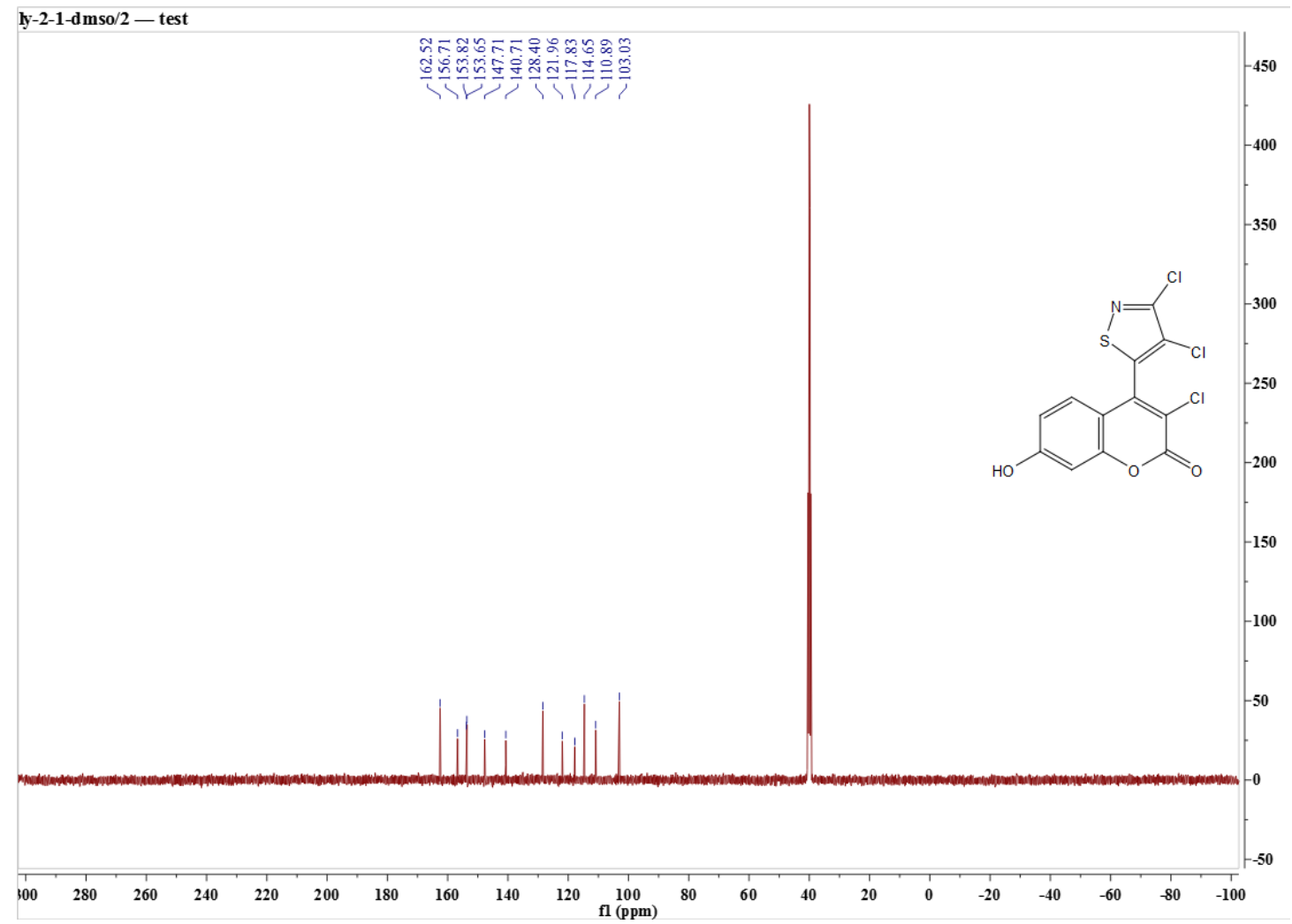

Figure $S 21$. The ${ }^{13} \mathrm{C}$ NMR (101 MHz, DMSO- $\left.d 6\right)$ of compound 7e.

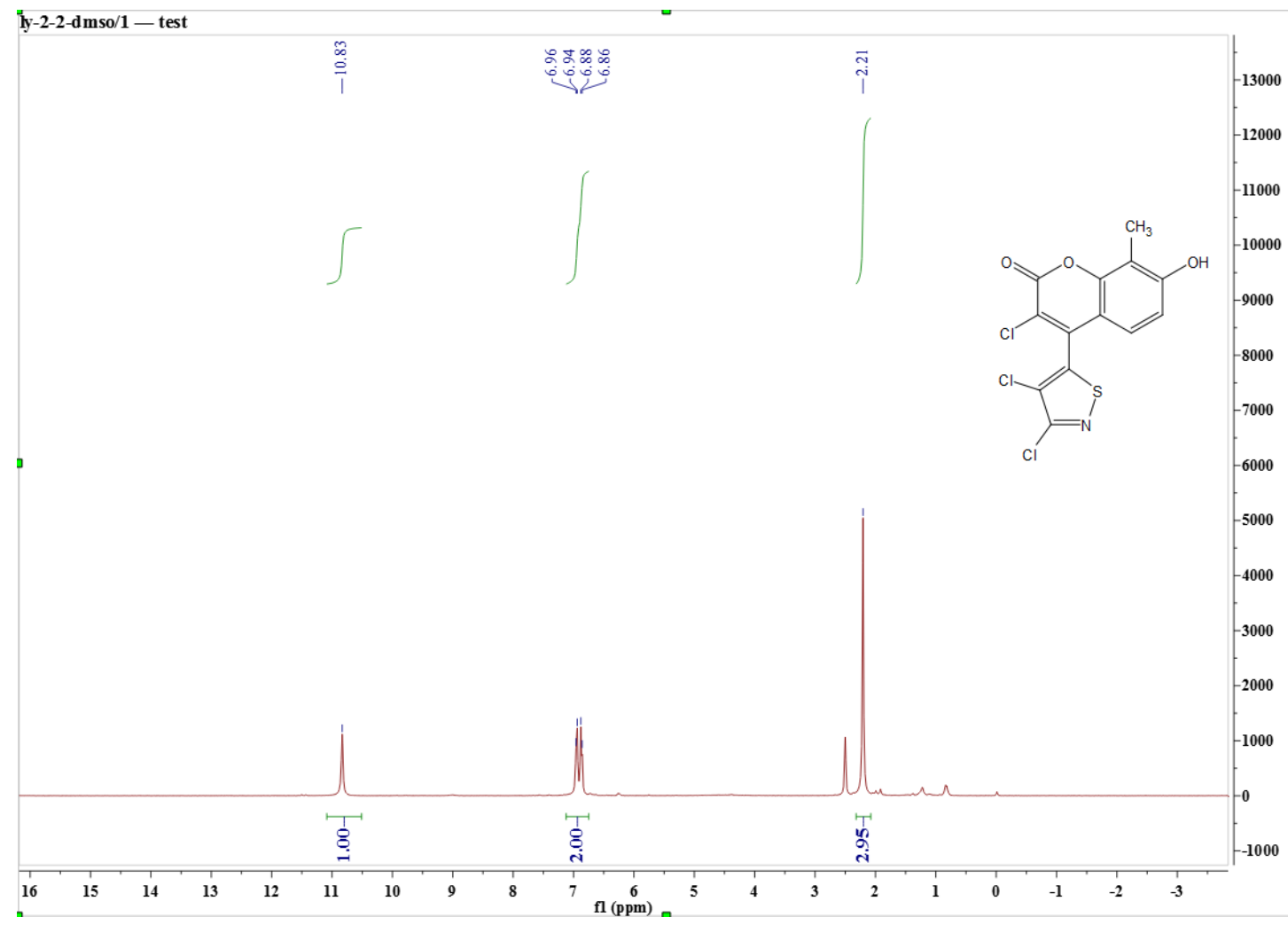

Figure $S 22$. The ${ }^{1} \mathrm{H}$ NMR (400 MHz, DMSO-d6) of compound $7 \mathbf{f}$. 


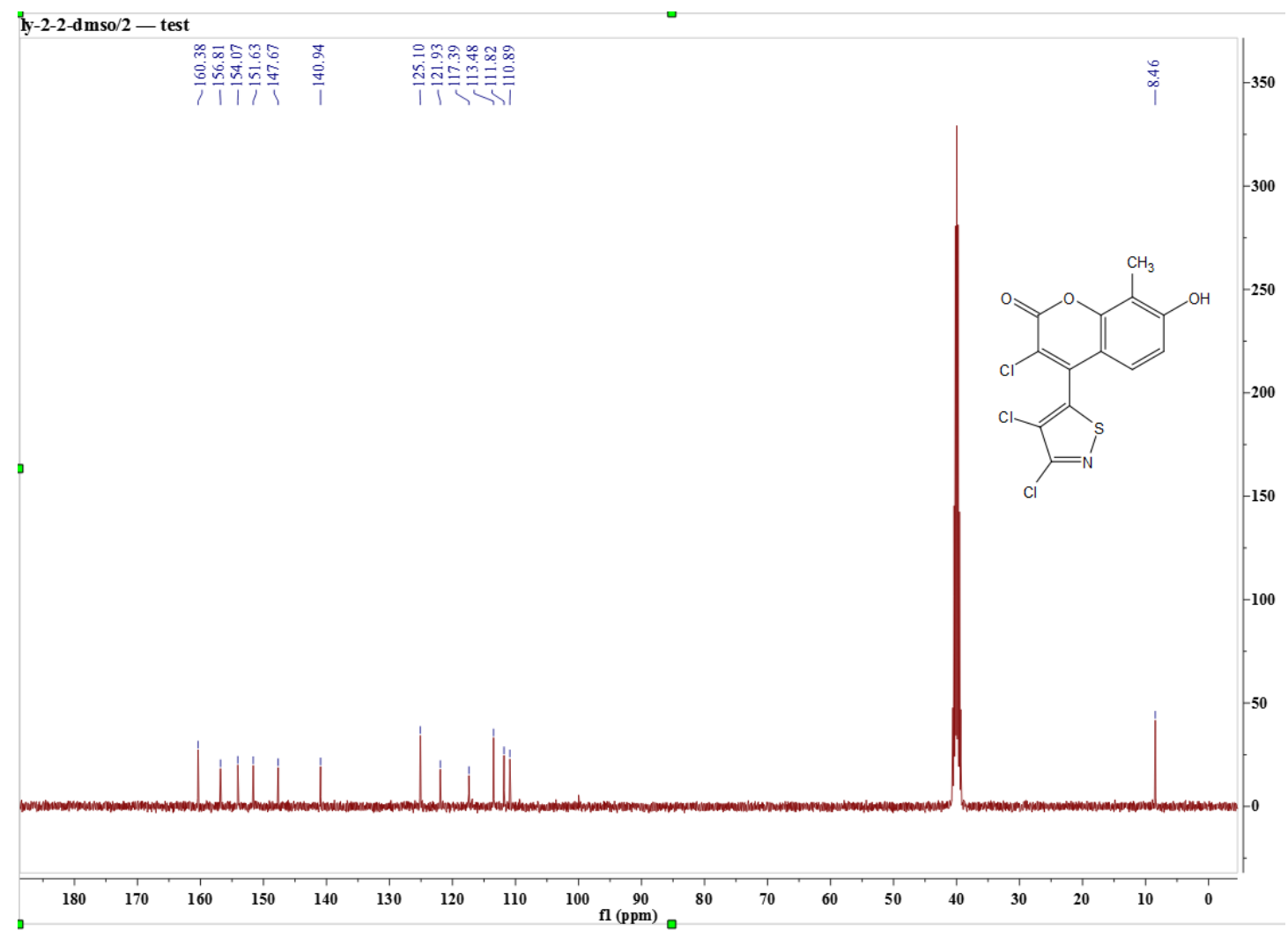

Figure S23. The ${ }^{13} \mathrm{C}$ NMR (101 MHz, DMSO- $\left.d 6\right)$ of compound $7 \mathbf{f}$.

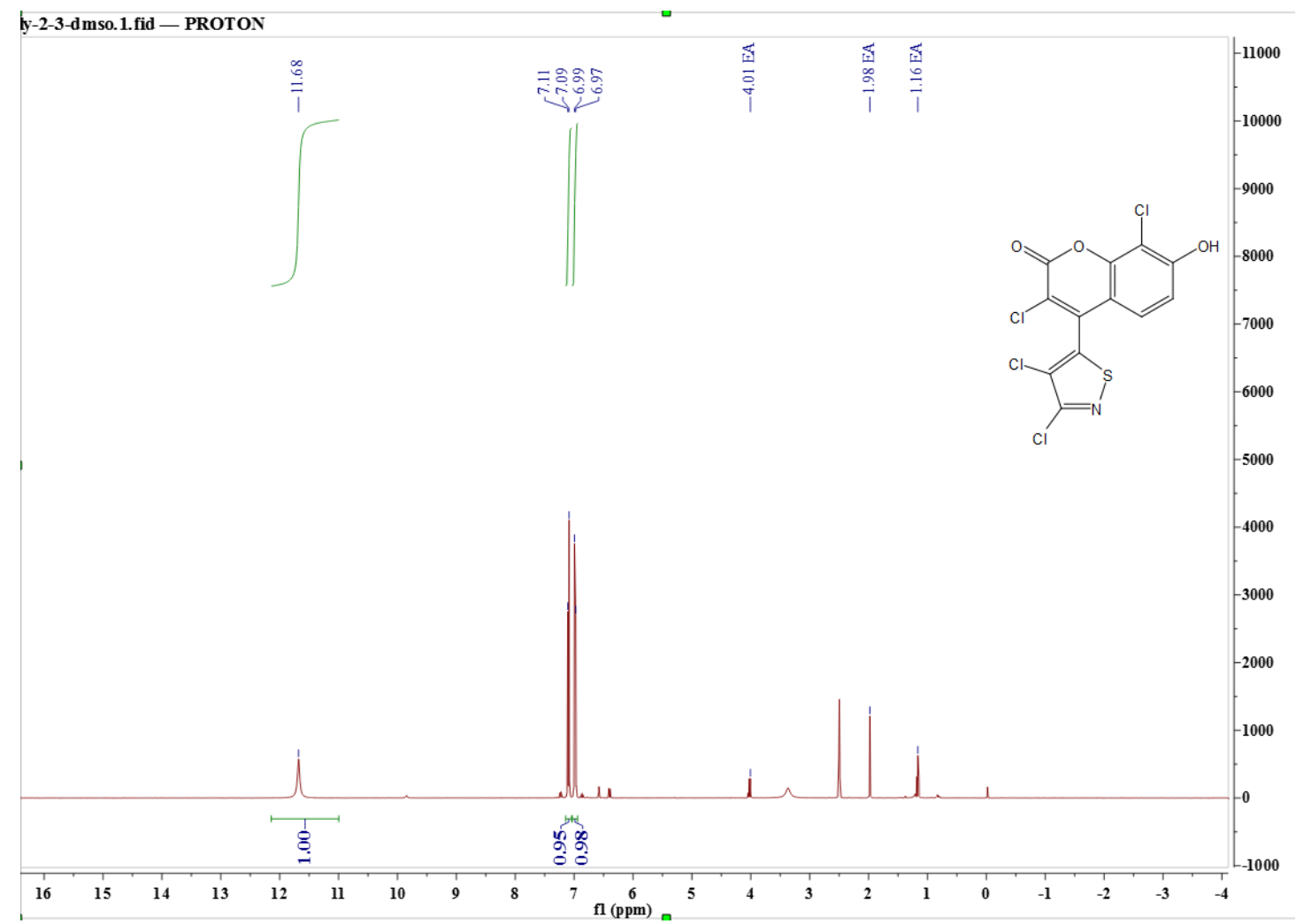

Figure $S 24$. The ${ }^{1} \mathrm{H}$ NMR (400 MHz, DMSO-d6) of compound 7 g. 


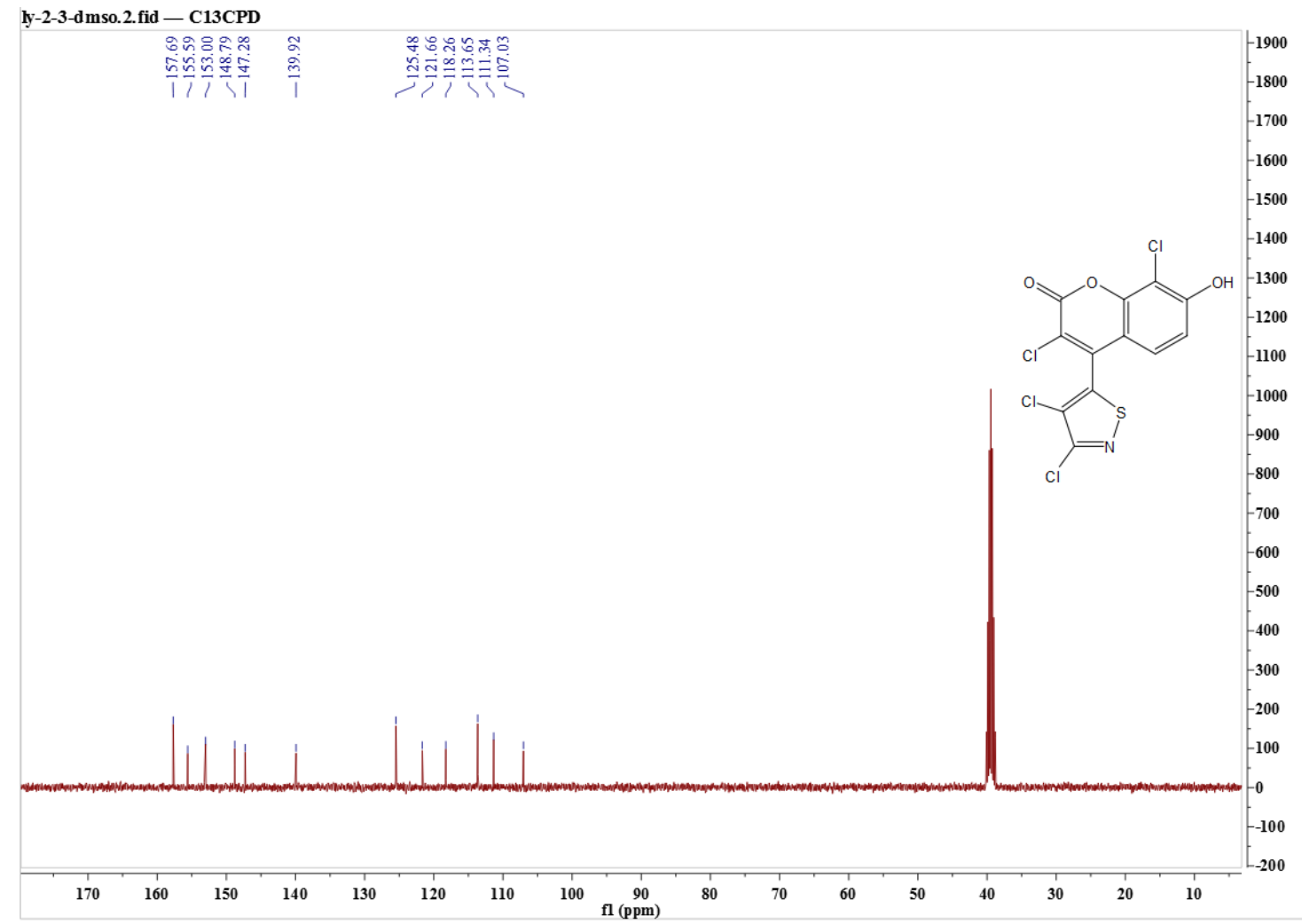

Figure S25. The ${ }^{13} \mathrm{C}$ NMR (101 MHz, DMSO-d6) of compound 7 g.

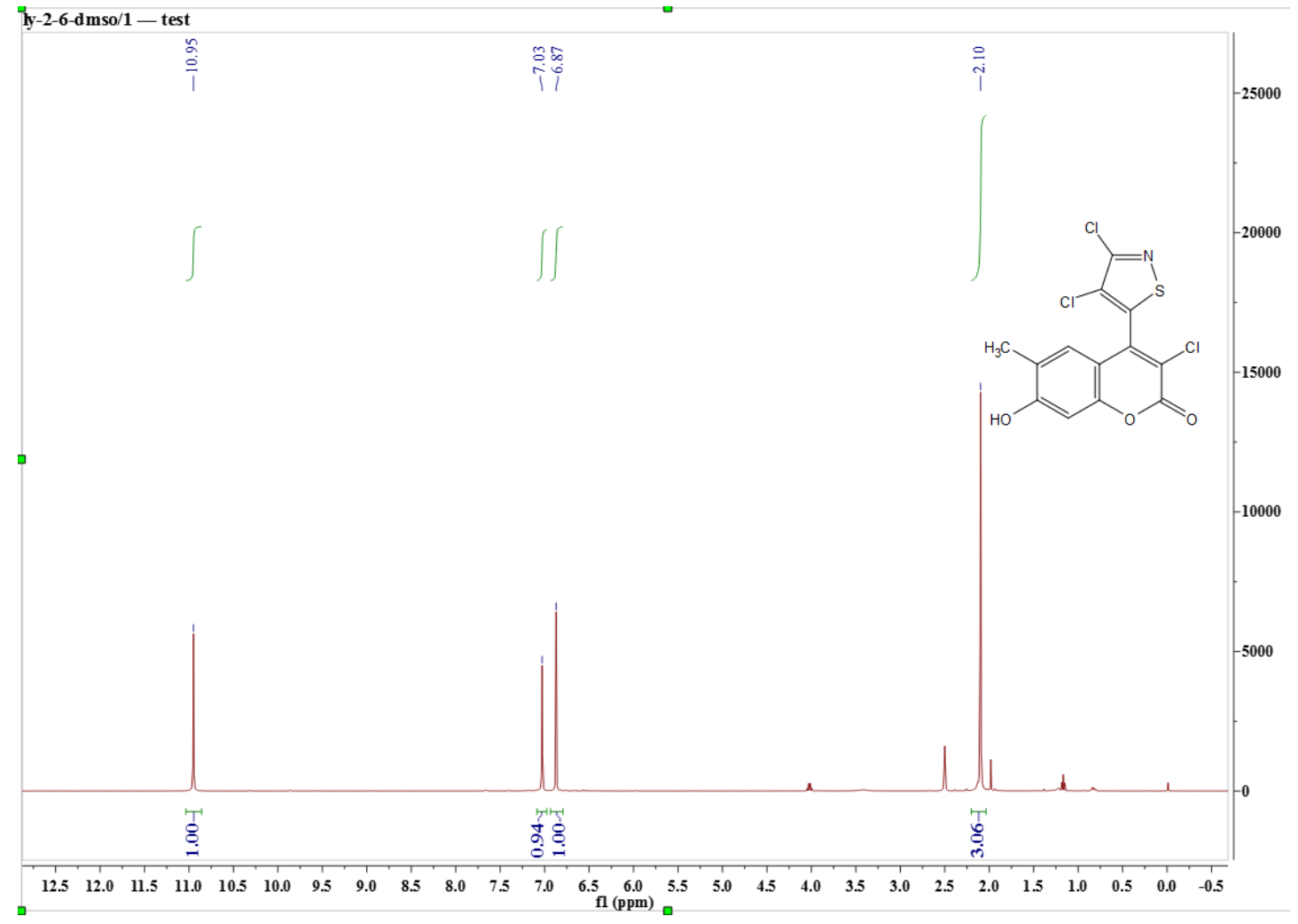

Figure S26. The ${ }^{1} \mathrm{H}$ NMR (400 MHz, DMSO-d6) of compound $7 \mathbf{h}$. 


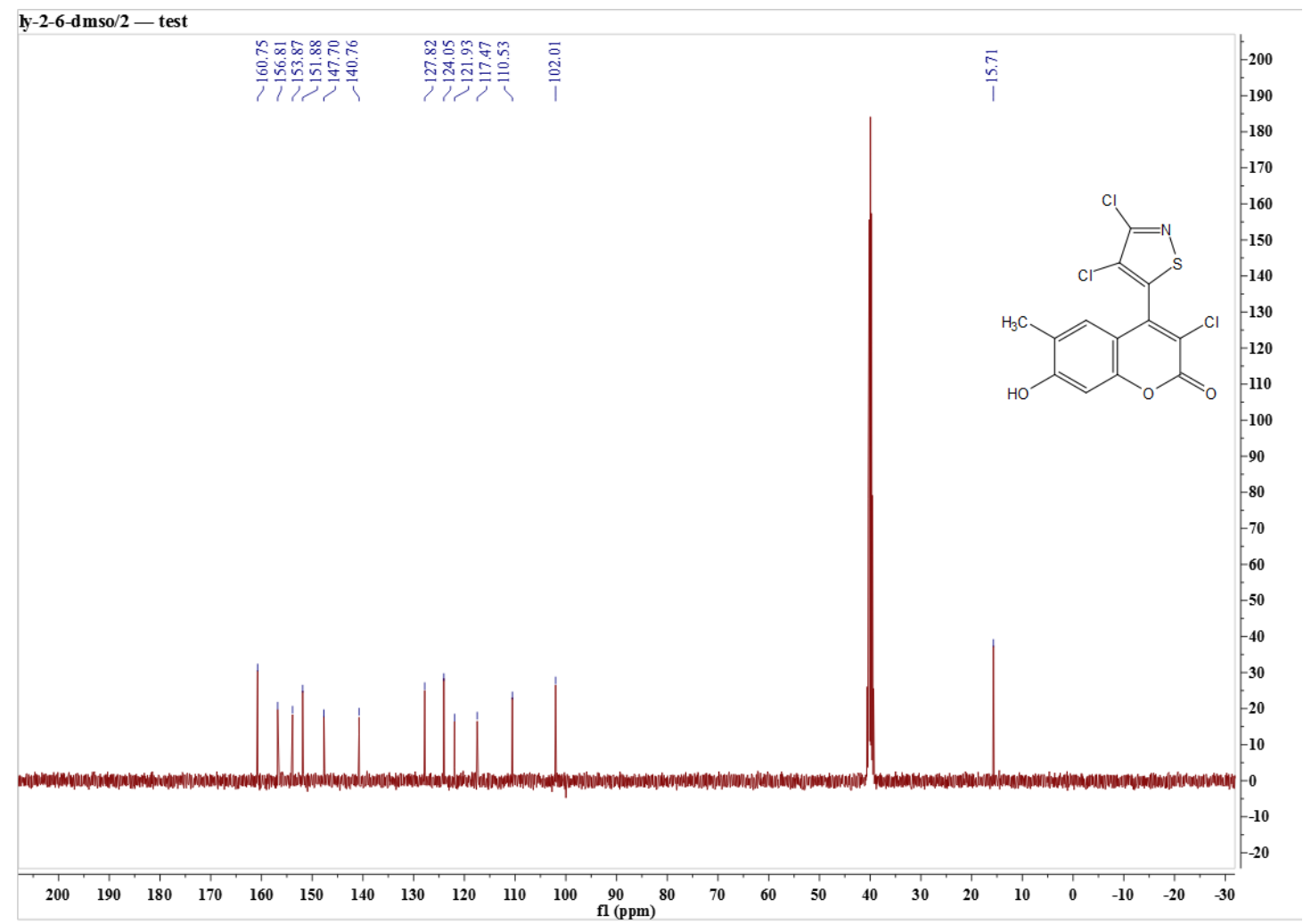

Figure S27. The ${ }^{13} \mathrm{C}$ NMR (101 MHz, DMSO- $\left.d 6\right)$ of compound $7 \mathbf{h}$.

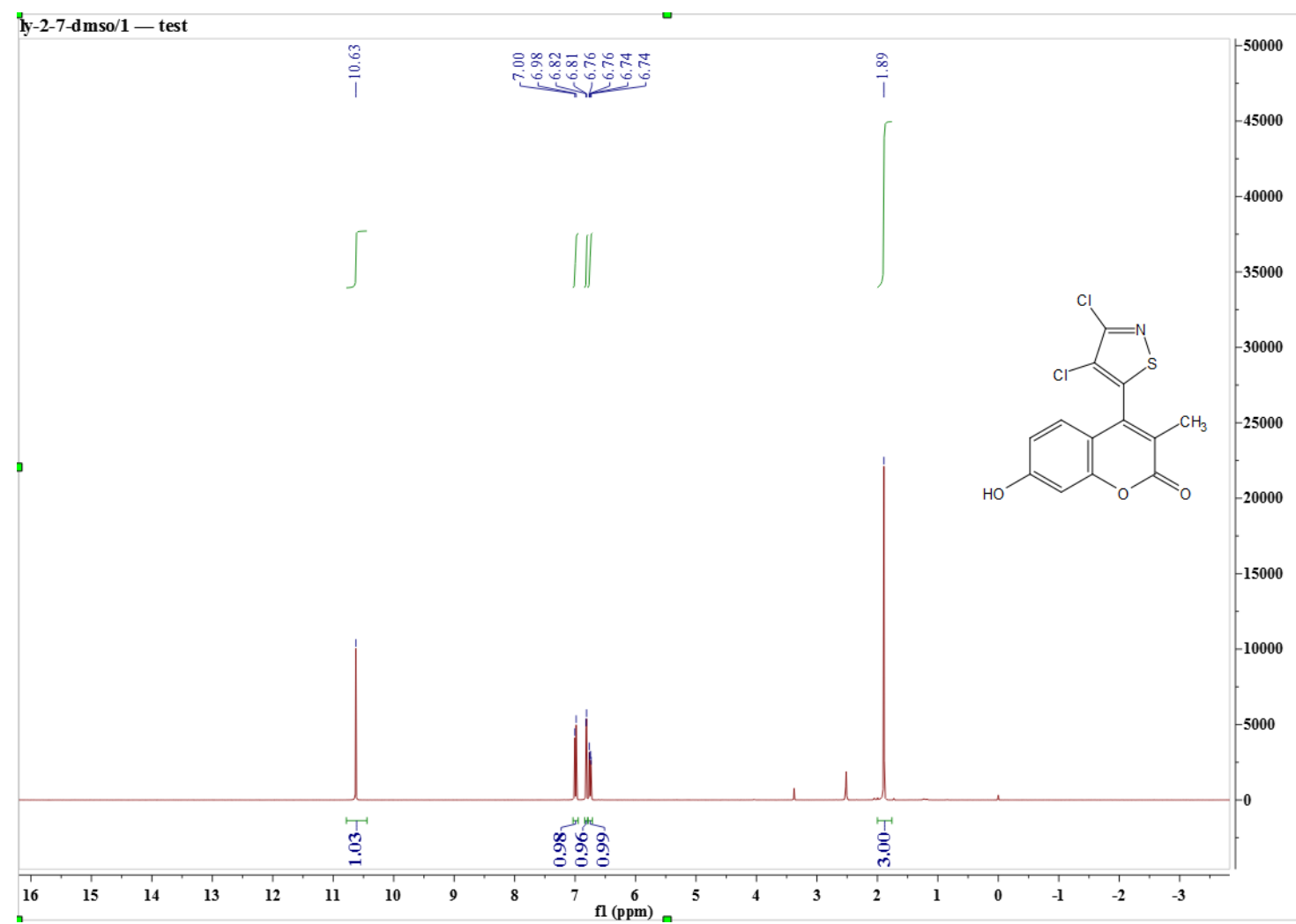

Figure $S 28$. The ${ }^{1} \mathrm{H}$ NMR (400 MHz, DMSO-d6) of compound 7 i. 


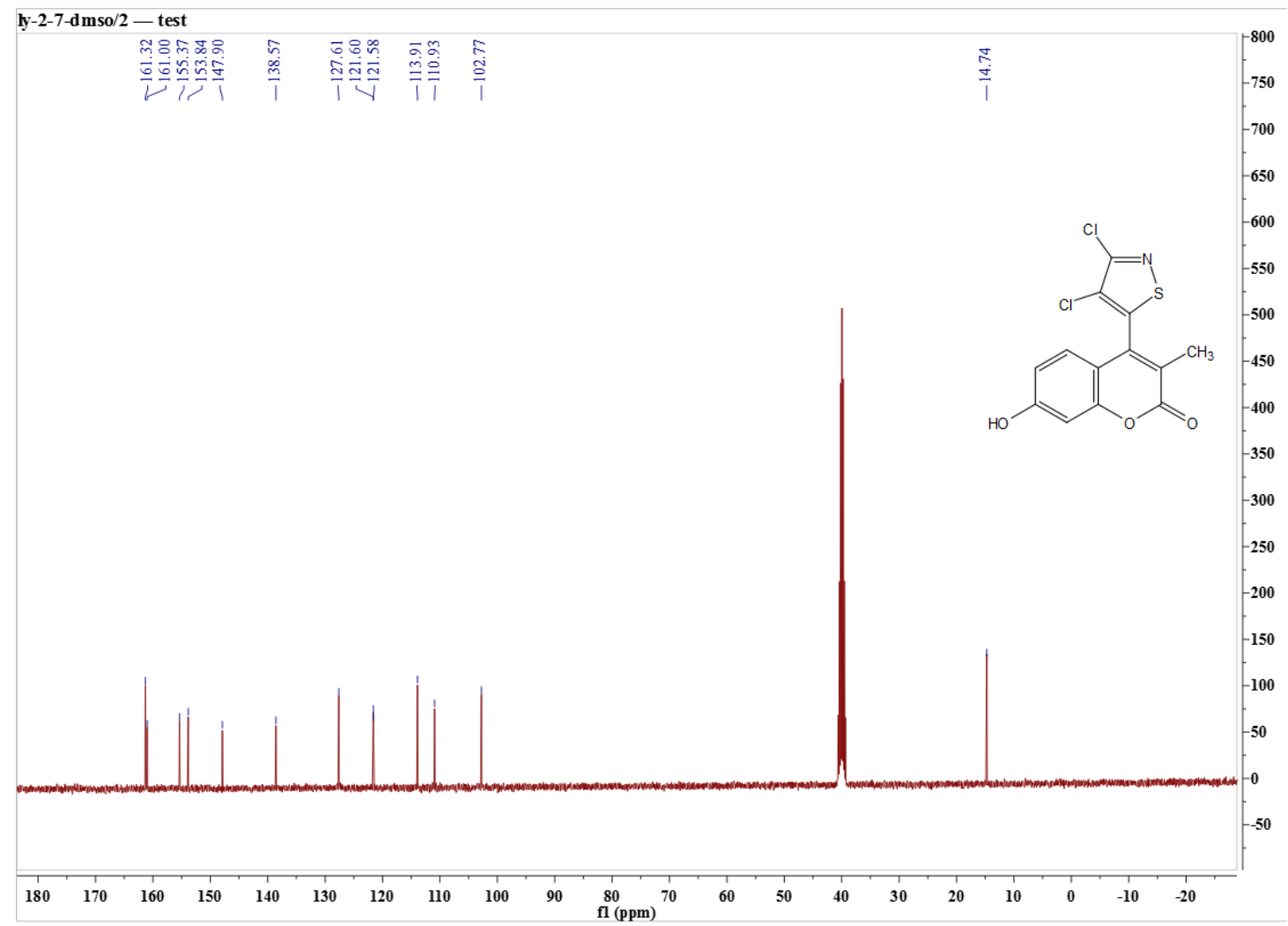

Figure S29. The ${ }^{13} \mathrm{C}$ NMR (101 MHz, DMSO- $\left.d 6\right)$ of compound $7 \mathbf{i}$.

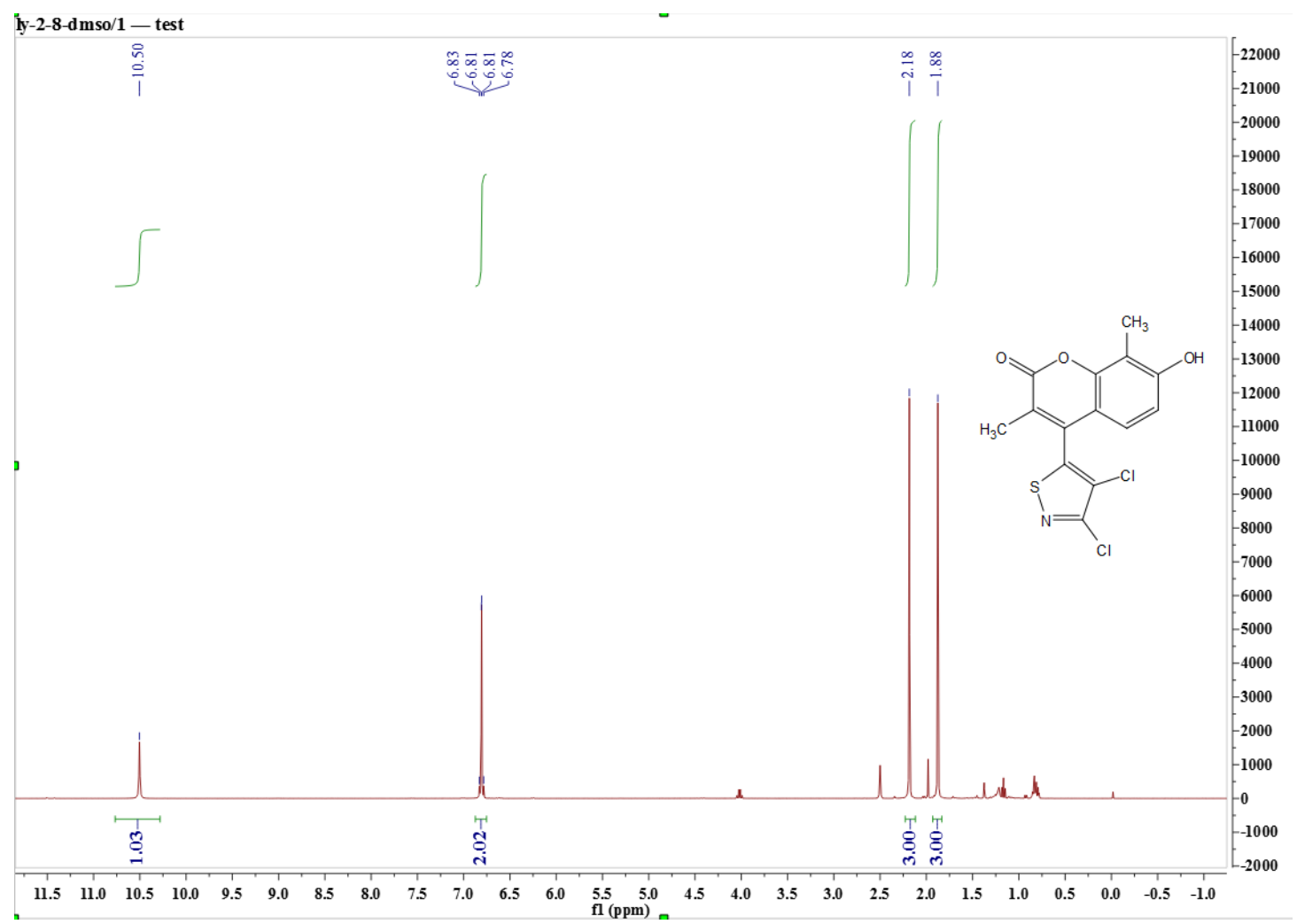

Figure S30. The ${ }^{1} \mathrm{H}$ NMR (400 MHz, DMSO-d6) of compound 7j. 


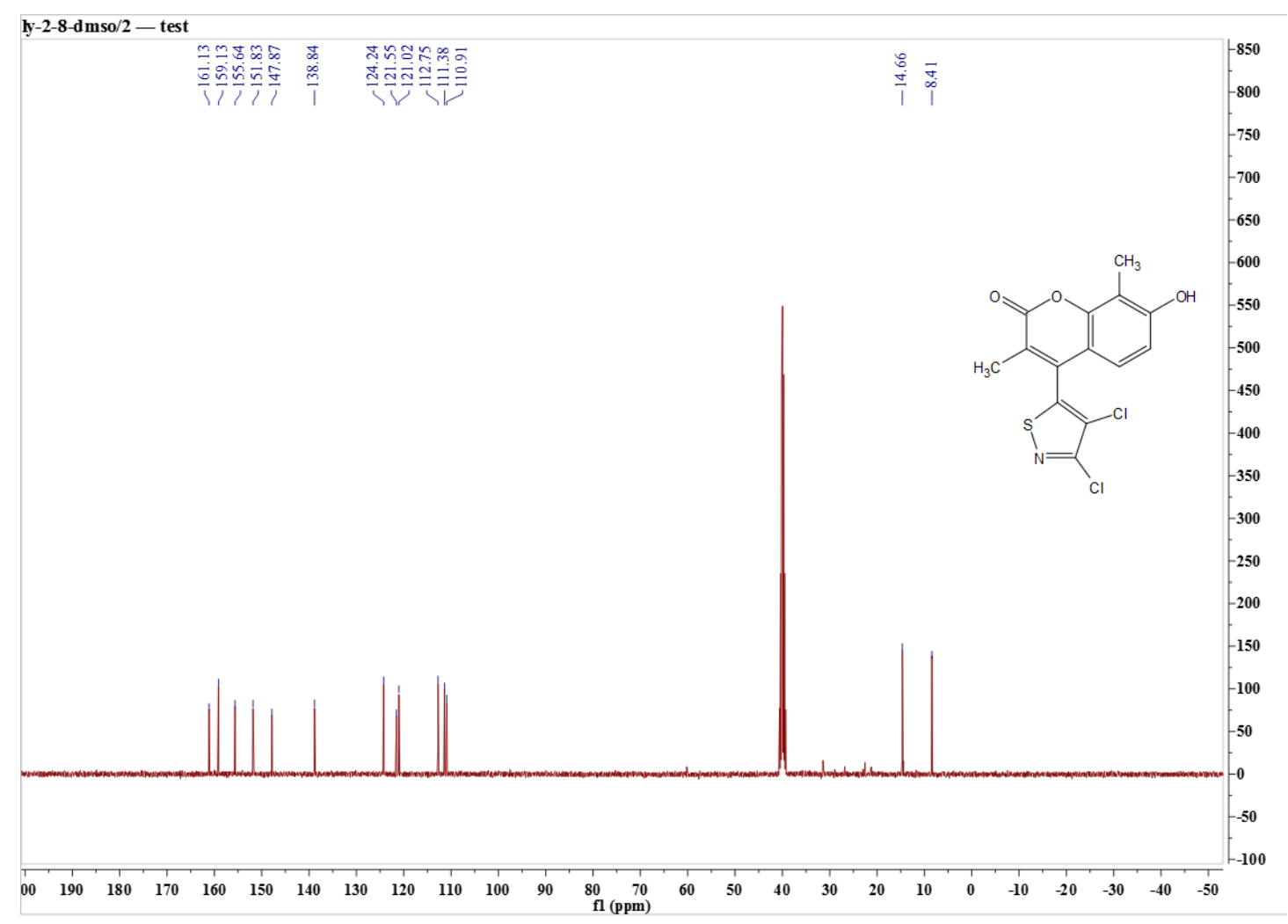

Figure S31. The ${ }^{13} \mathrm{C}$ NMR (101 MHz, DMSO-d6) of compound 7j.

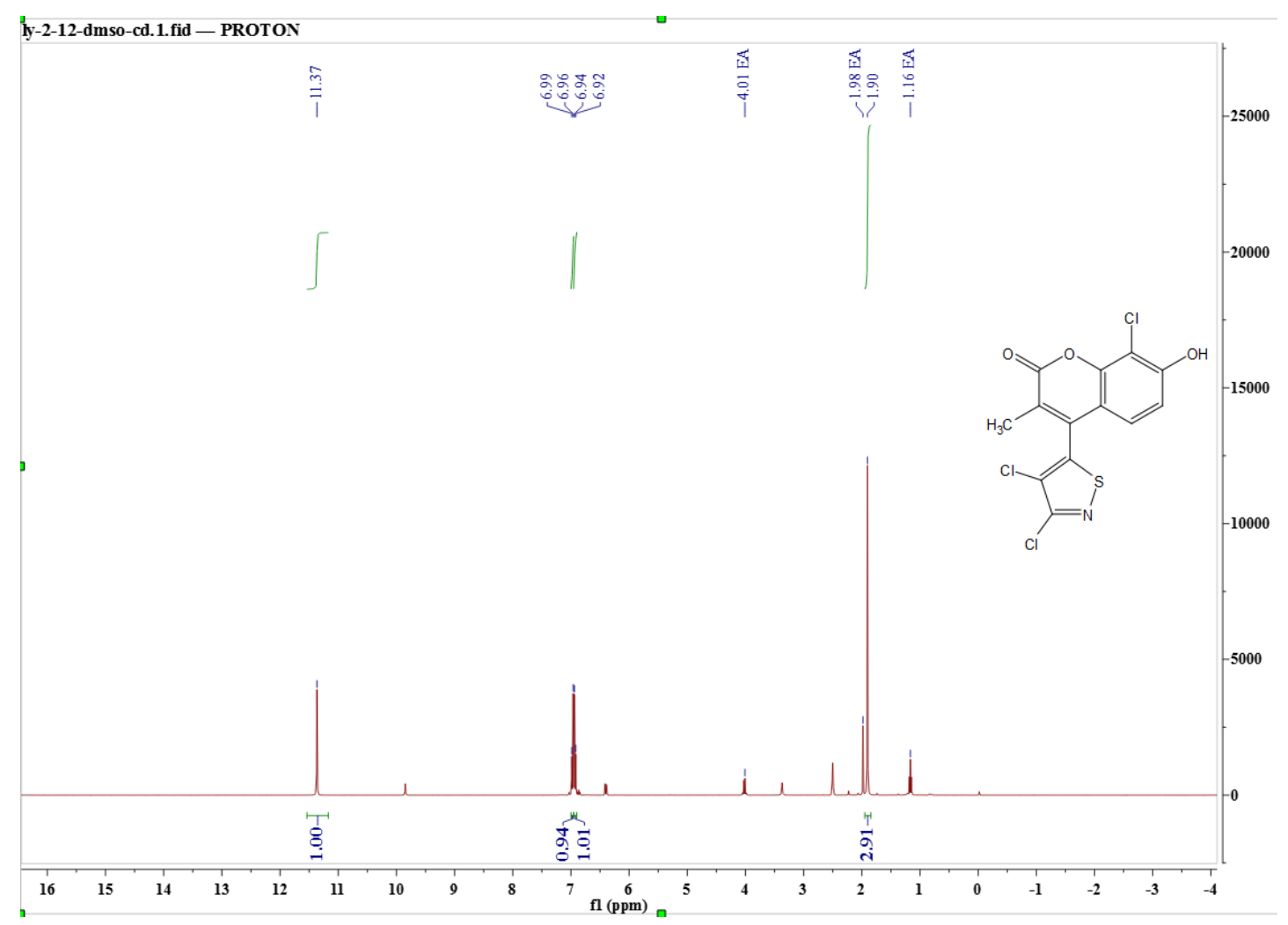

Figure S32. The ${ }^{1} \mathrm{H}$ NMR (400 MHz, DMSO-d6) of compound $7 \mathbf{k}$. 


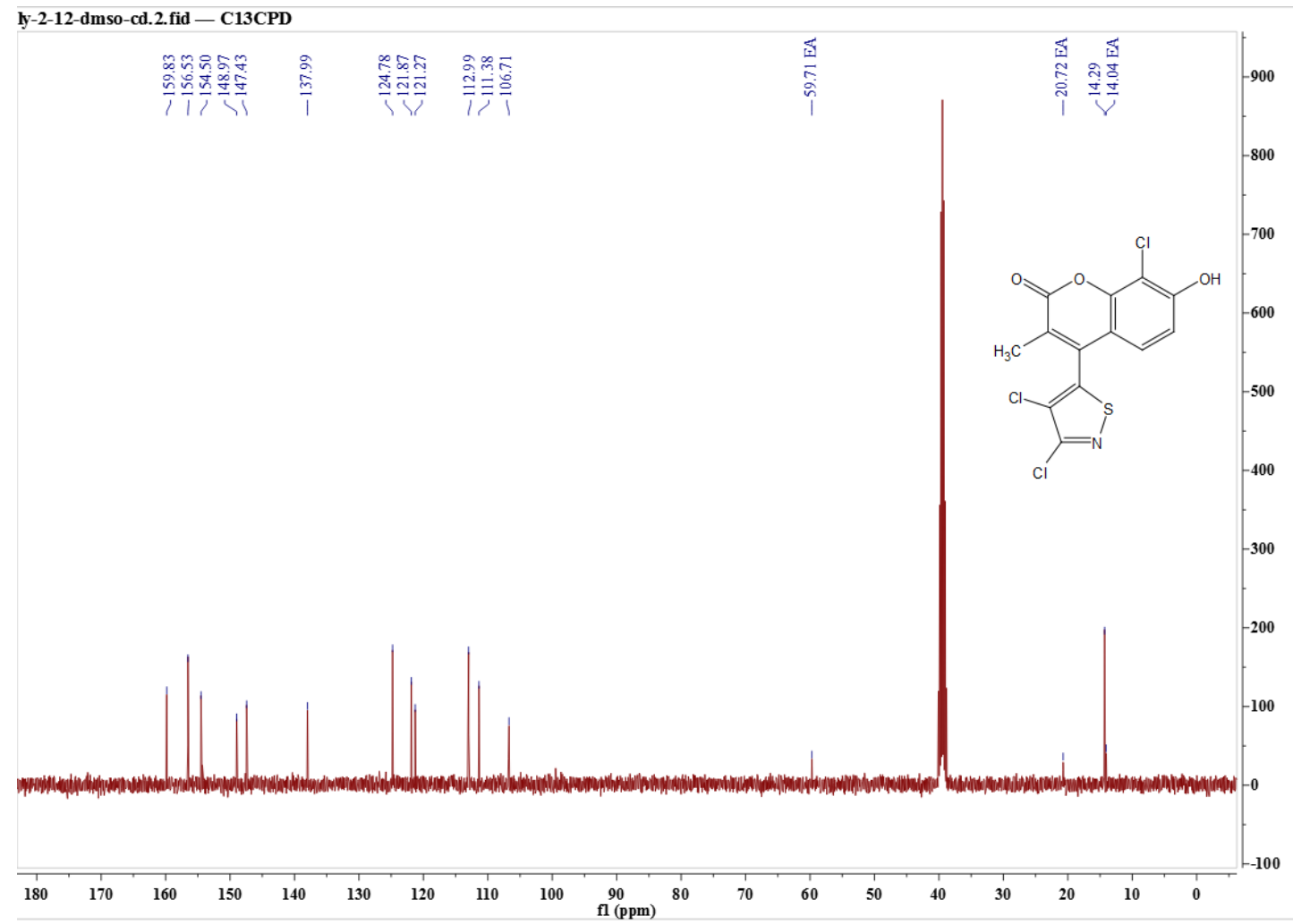

Figure S33. The ${ }^{13} \mathrm{C}$ NMR (101 MHz, DMSO-d6) of compound $7 \mathbf{k}$.

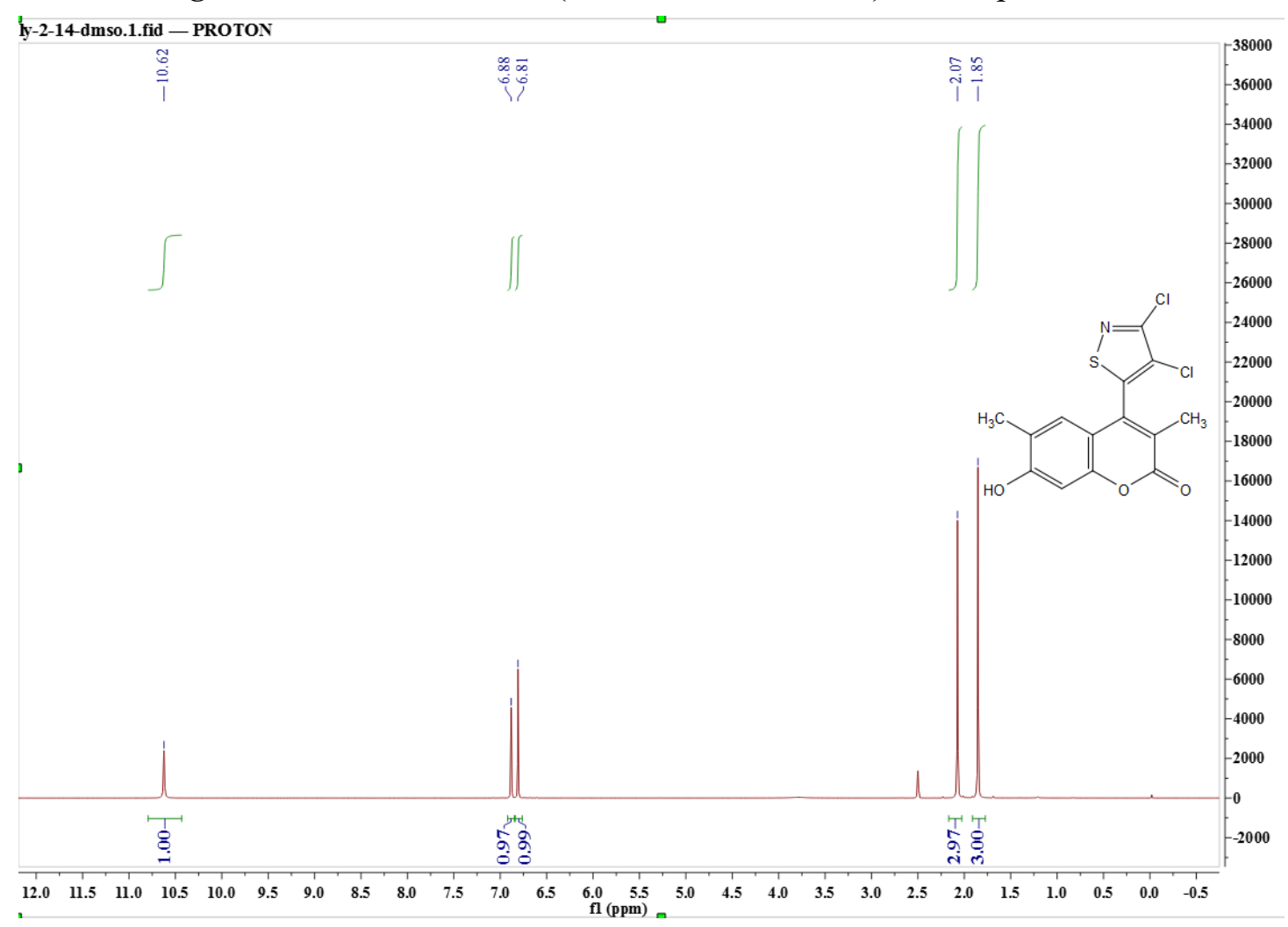

Figure S34. The ${ }^{1} \mathrm{H}$ NMR (400 MHz, DMSO-d6) of compound 71. 


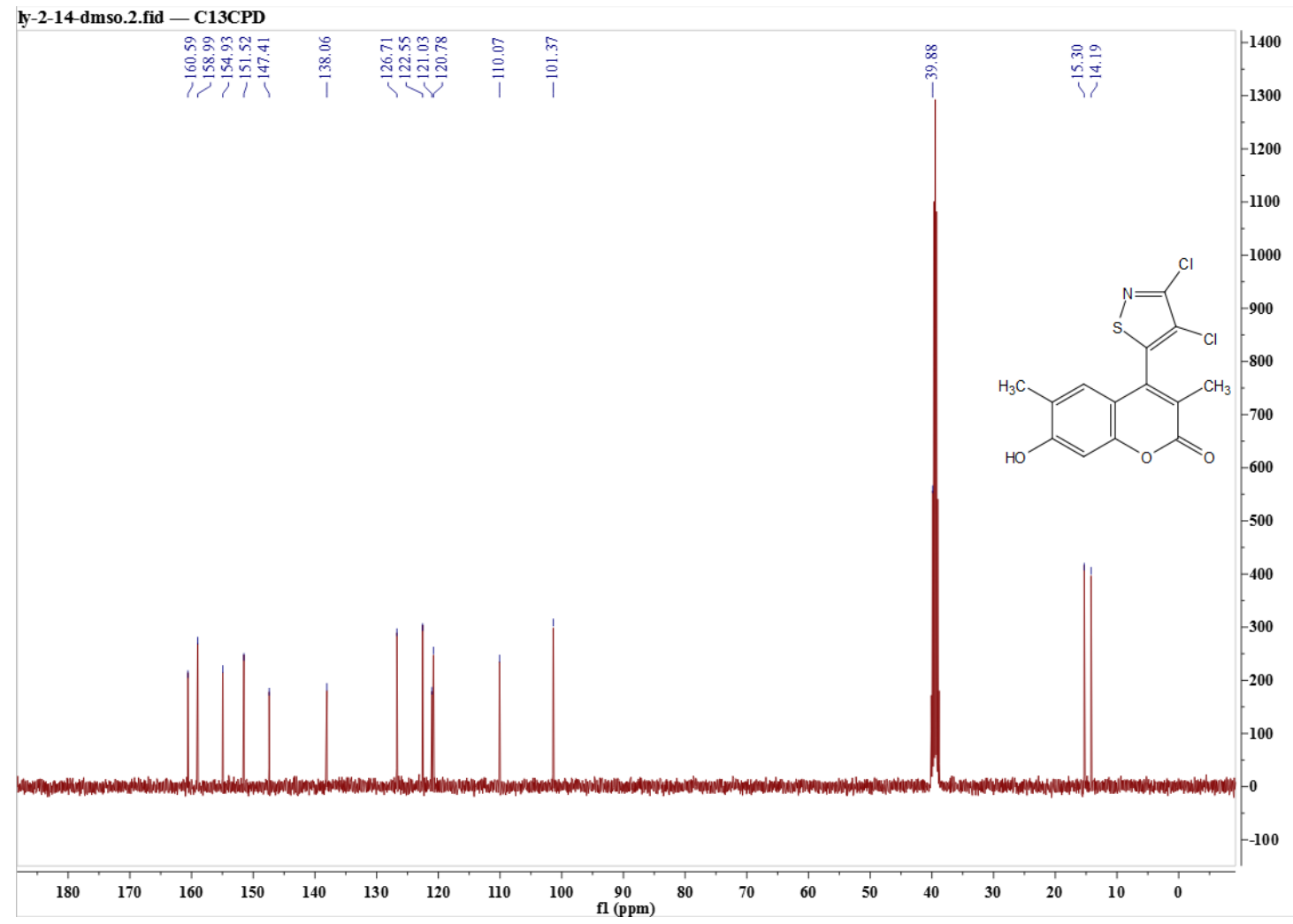

Figure S35. The ${ }^{13} \mathrm{C}$ NMR (101 MHz, DMSO-d6) of compound 71.

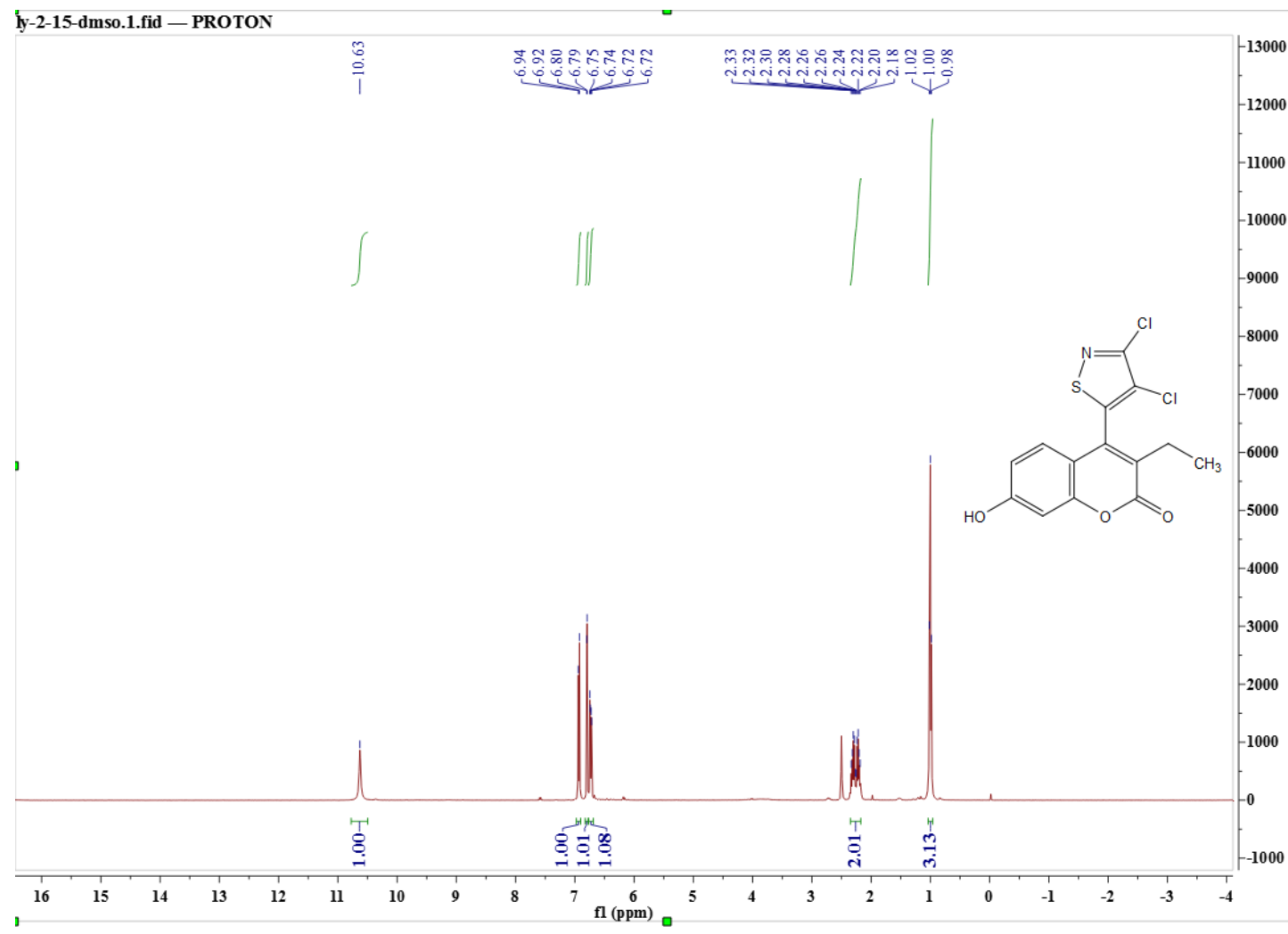

Figure S36. The ${ }^{1} \mathrm{H}$ NMR (400 MHz, DMSO-d6) of compound $7 \mathbf{m}$. 


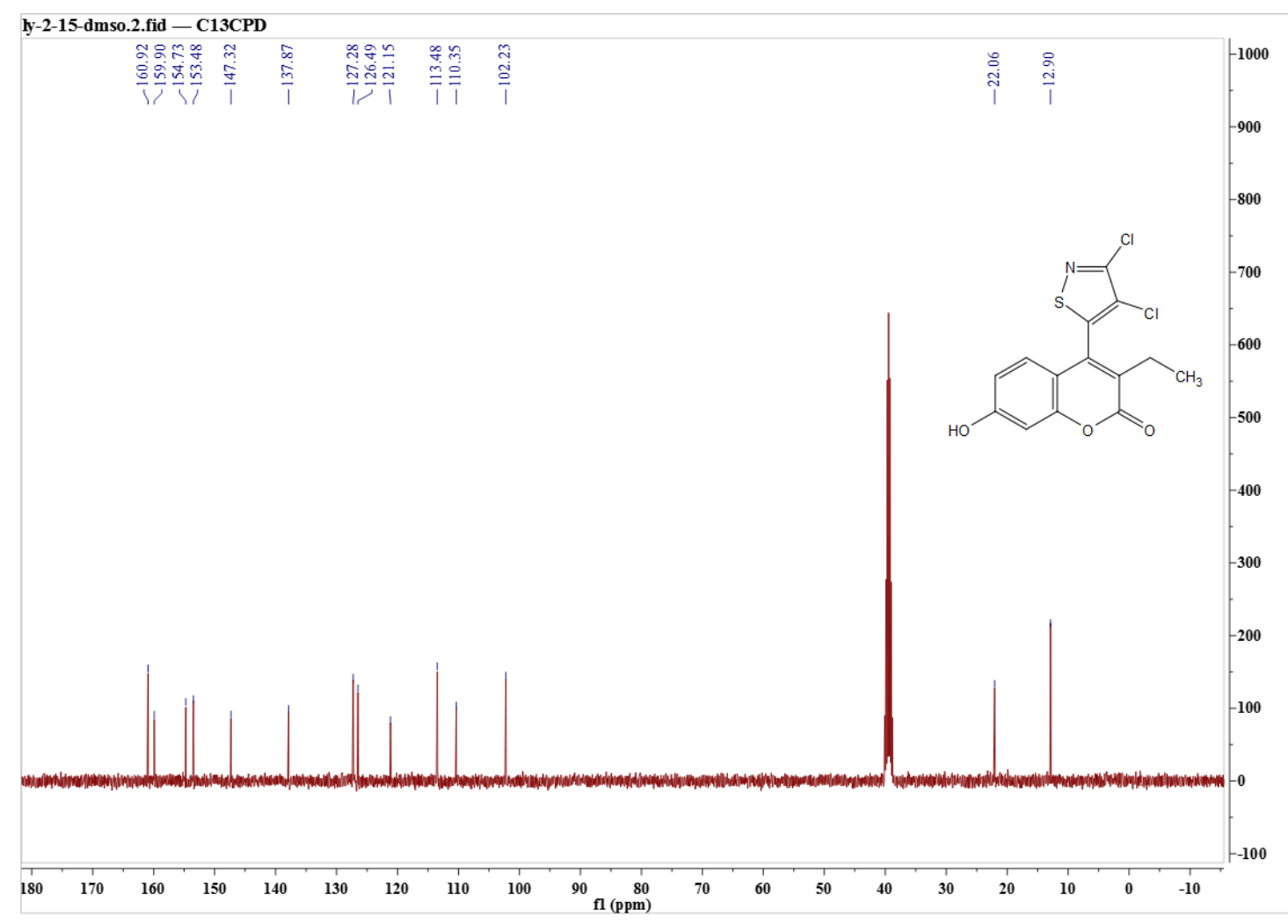

Figure S37. The ${ }^{13} \mathrm{C}$ NMR (101 MHz, DMSO-d6) of compound $7 \mathbf{m}$.

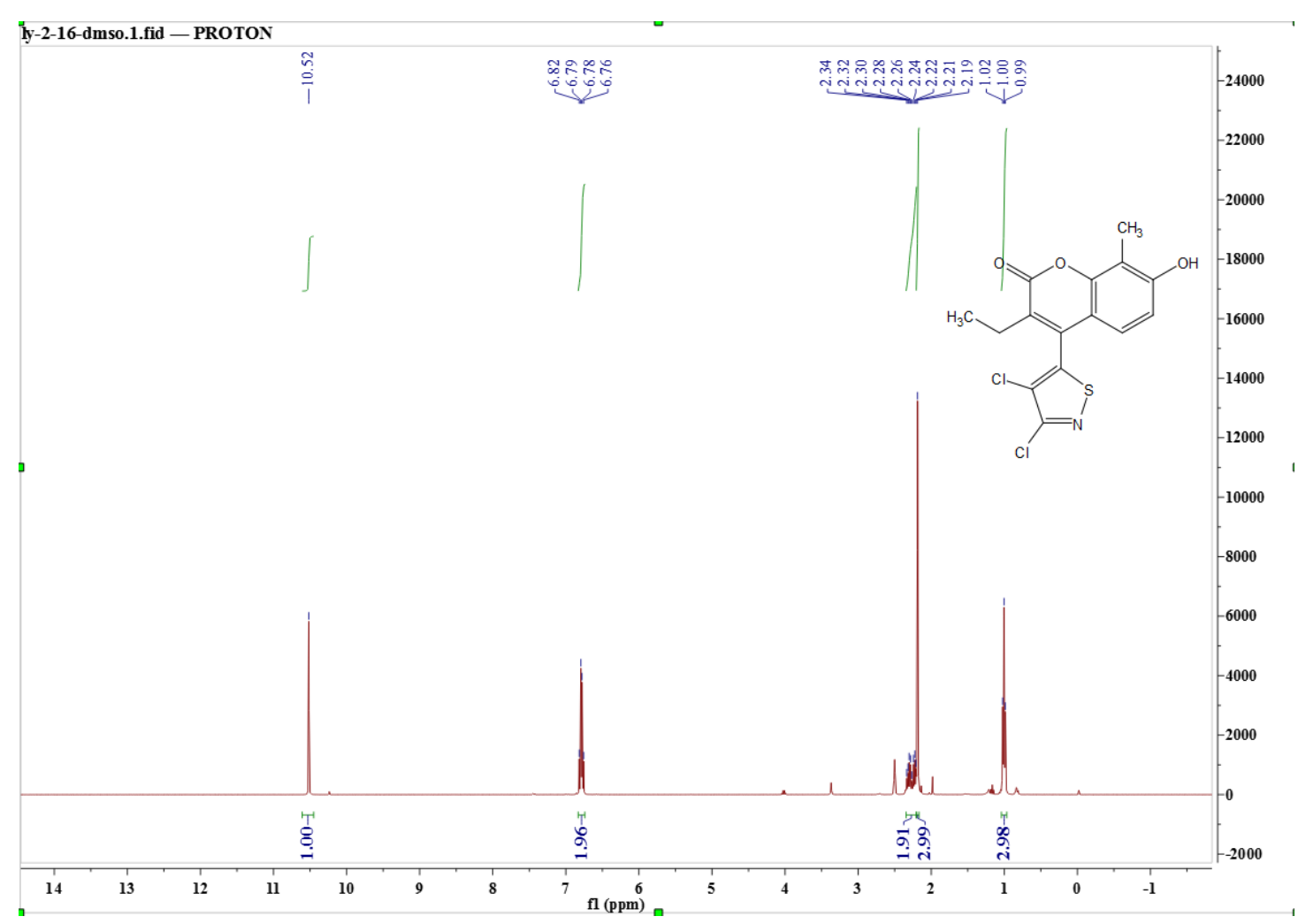

Figure S38. The ${ }^{1} \mathrm{H}$ NMR (400 MHz, DMSO-d6) of compound 7n. 


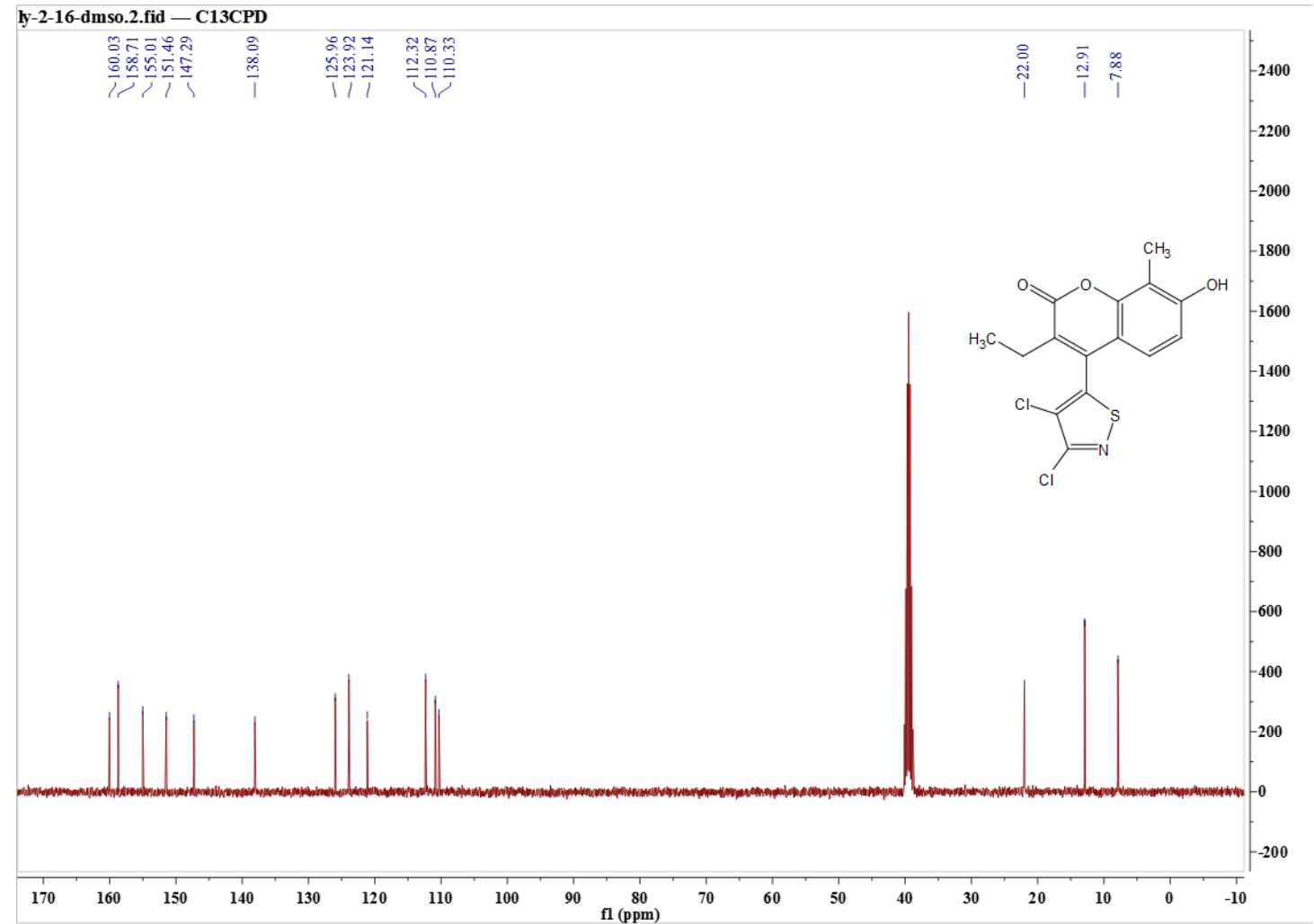

Figure S39. The ${ }^{13} \mathrm{C}$ NMR (101 MHz, DMSO-d6) of compound $7 \mathbf{n}$.

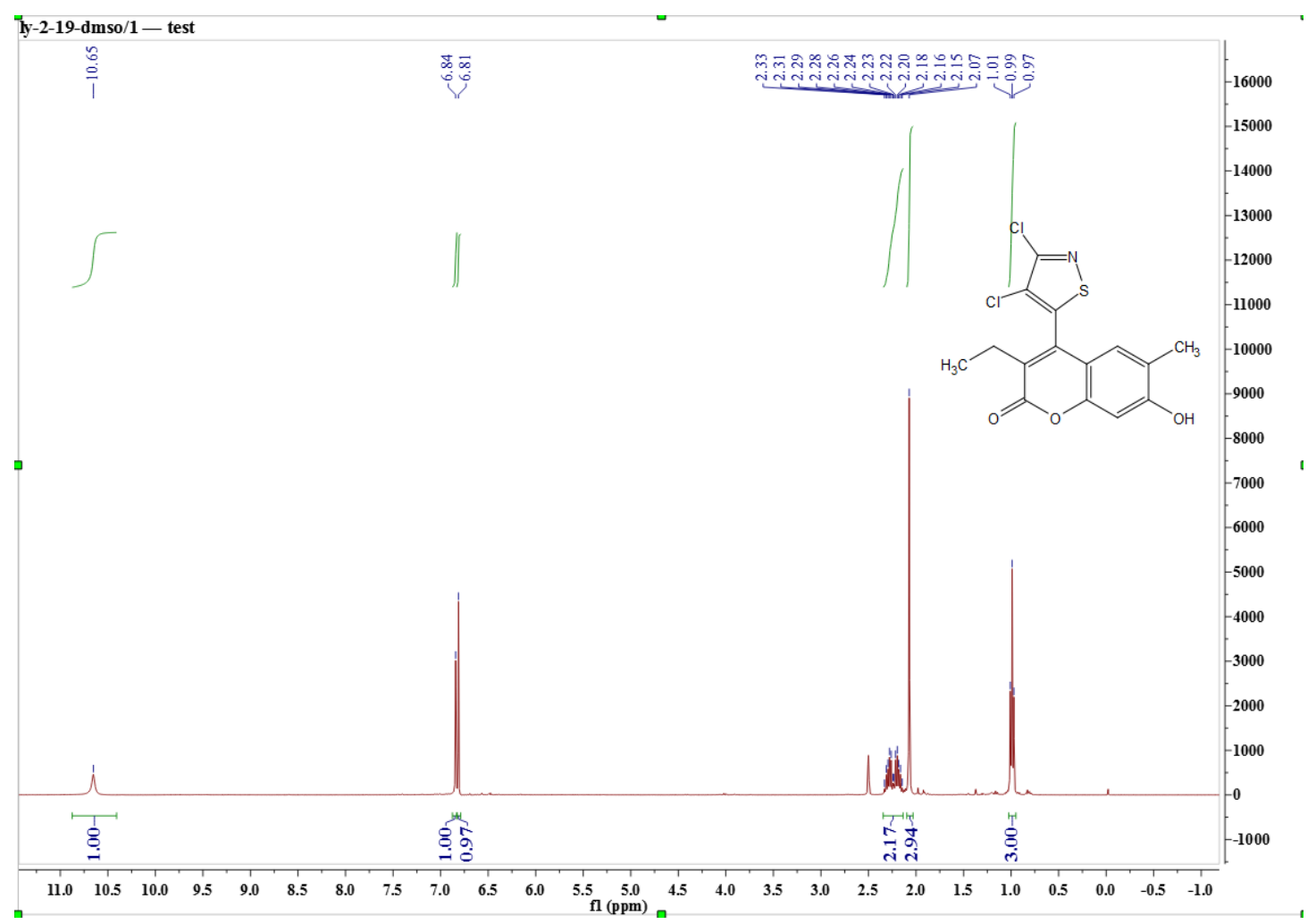

Figure S40. The ${ }^{1} \mathrm{H}$ NMR (400 MHz, DMSO-d6) of compound $7 \mathbf{0}$. 


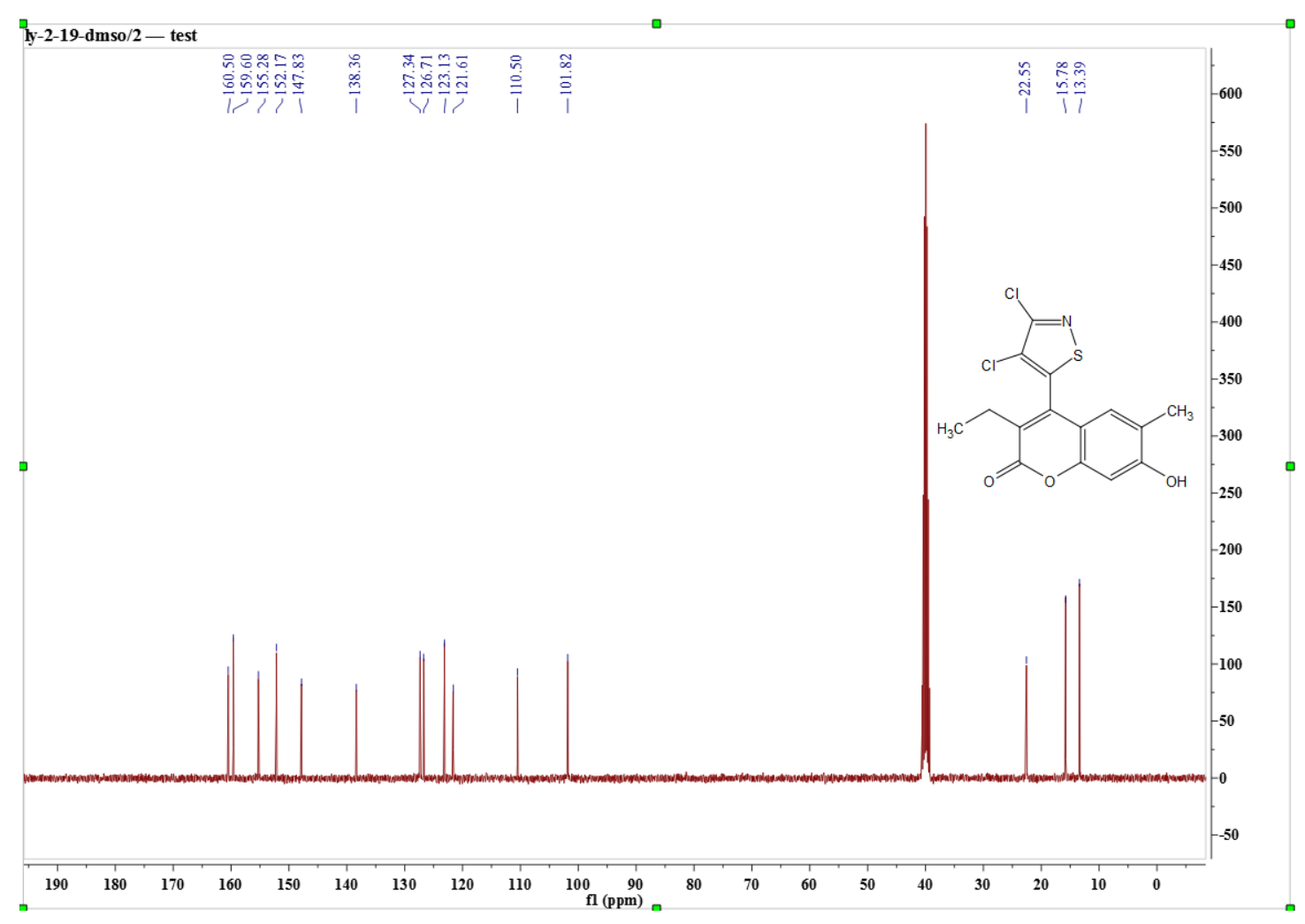

Figure S41. The ${ }^{13} \mathrm{C}$ NMR (101 MHz, DMSO- $\left.d 6\right)$ of compound $7 \mathbf{0}$.

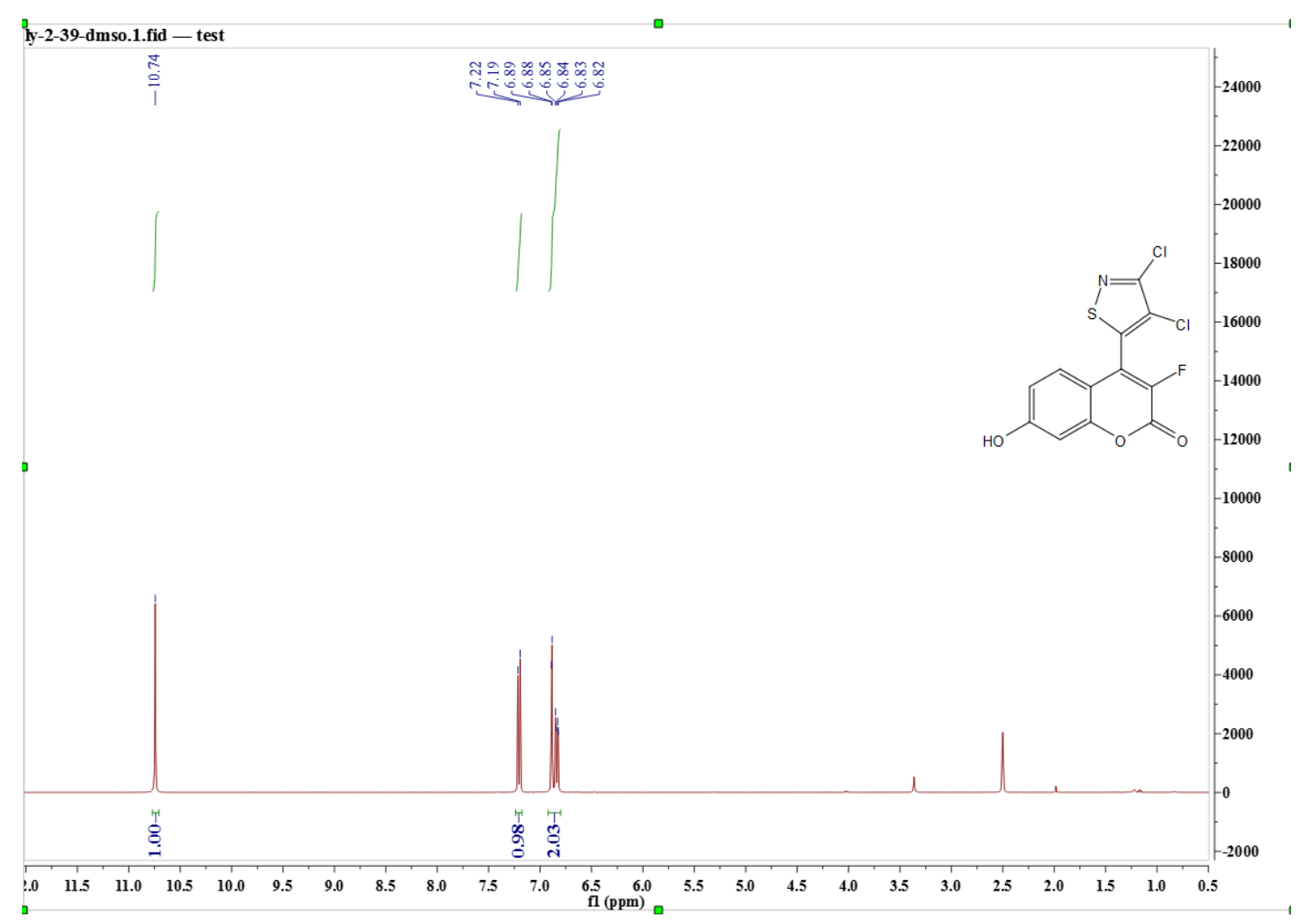

Figure S42. The ${ }^{1} \mathrm{H}$ NMR (400 MHz, DMSO-d6) of compound 7p. 


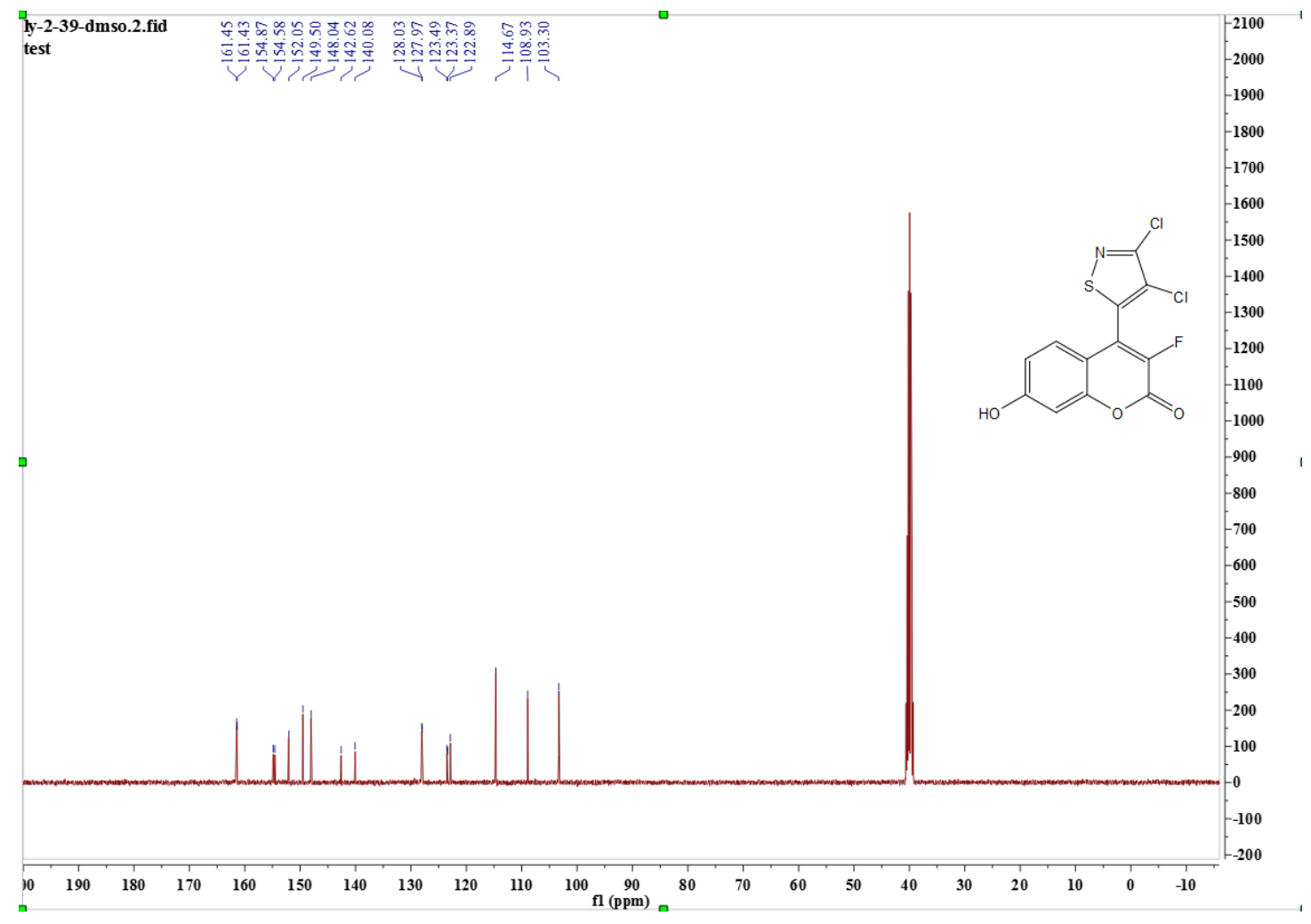

Figure S43. The ${ }^{13} \mathrm{C}$ NMR (101 MHz, DMSO-d6) of compound 7p.

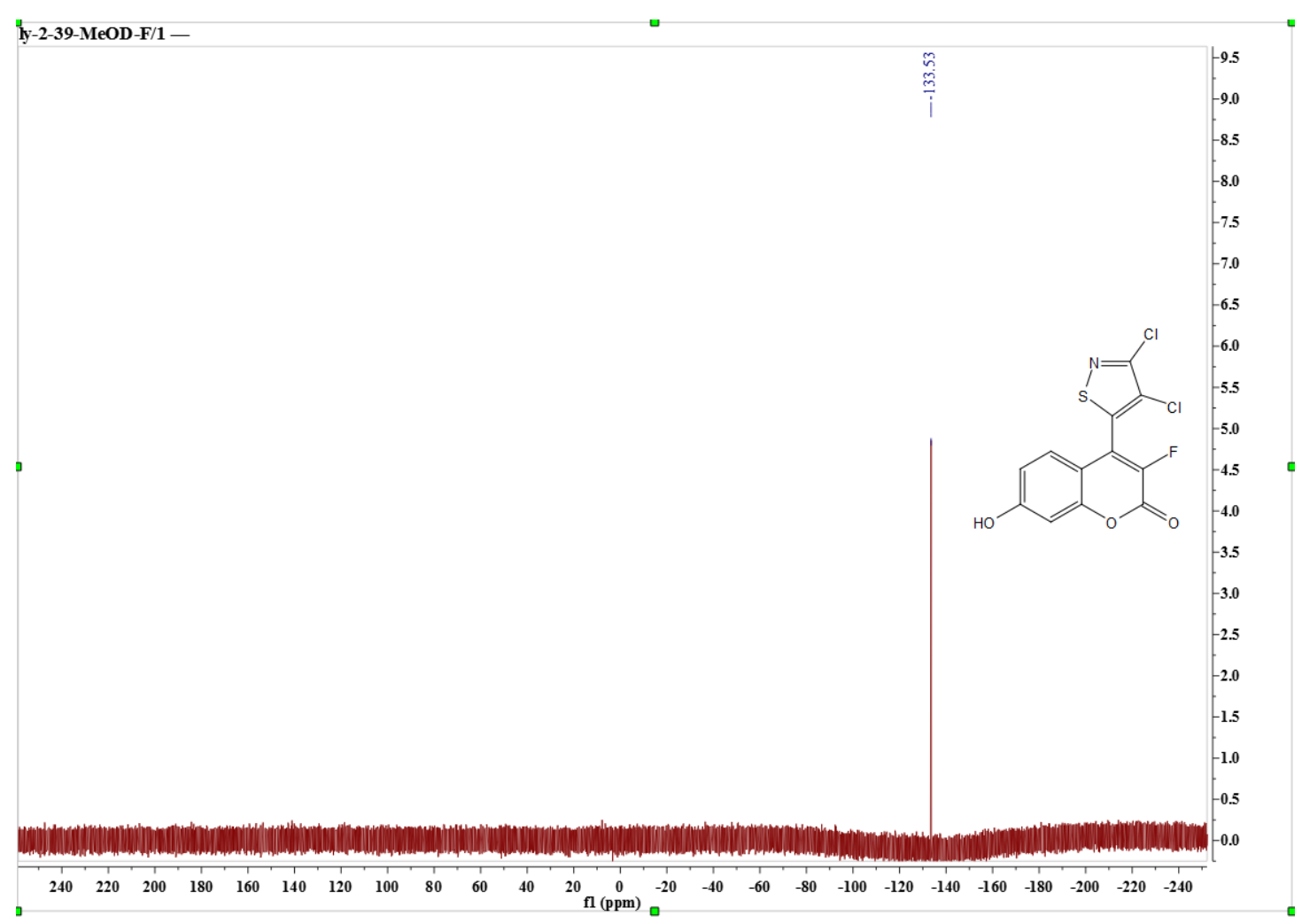

Figure S44. The ${ }^{19} \mathrm{~F}$ NMR (376 MHz, CD $\left.3 \mathrm{OD}\right)$ of compound $7 \mathbf{p}$. 


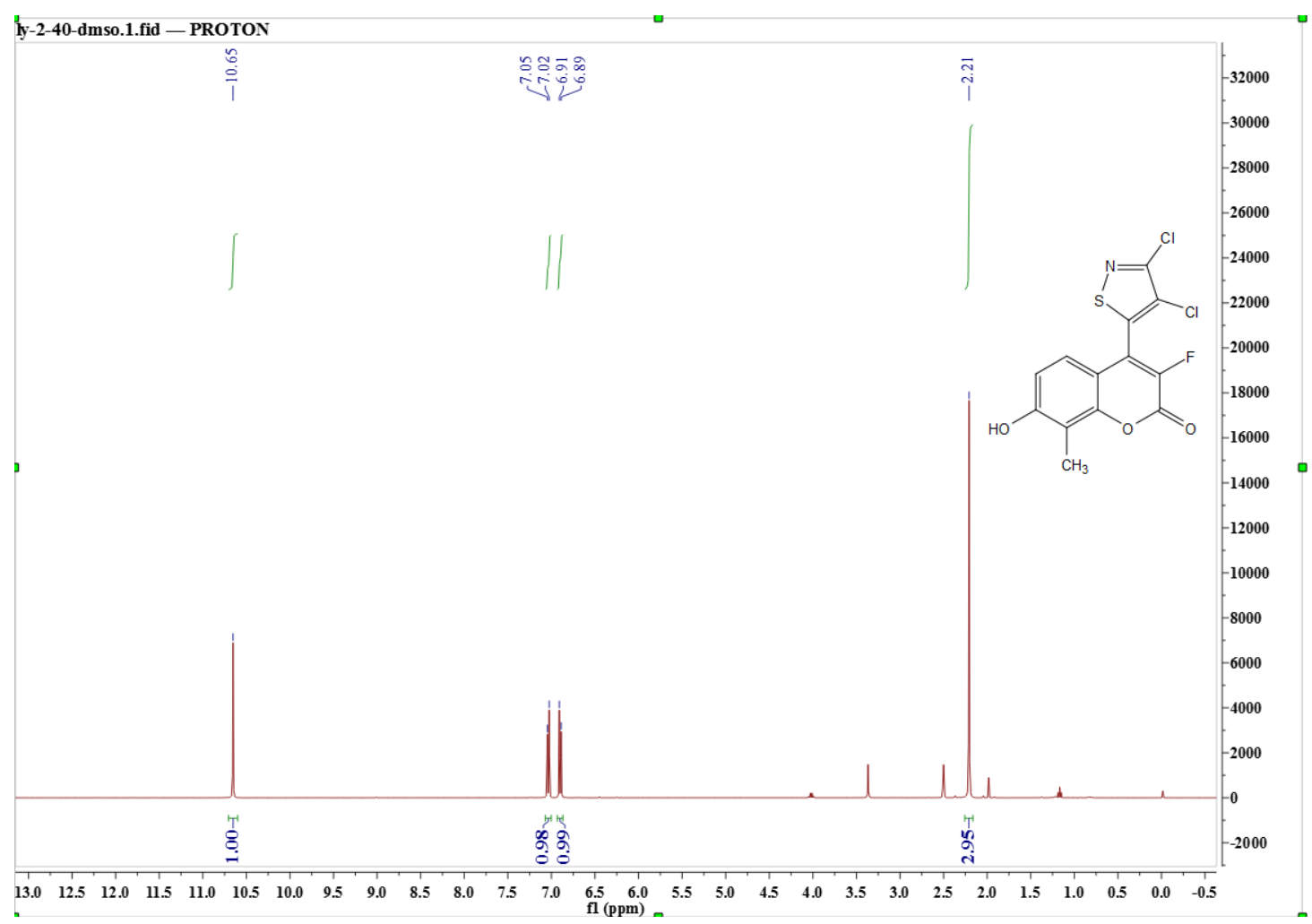

Figure S45. The ${ }^{1} \mathrm{H}$ NMR (400 MHz, DMSO-d6) of compound 7q.

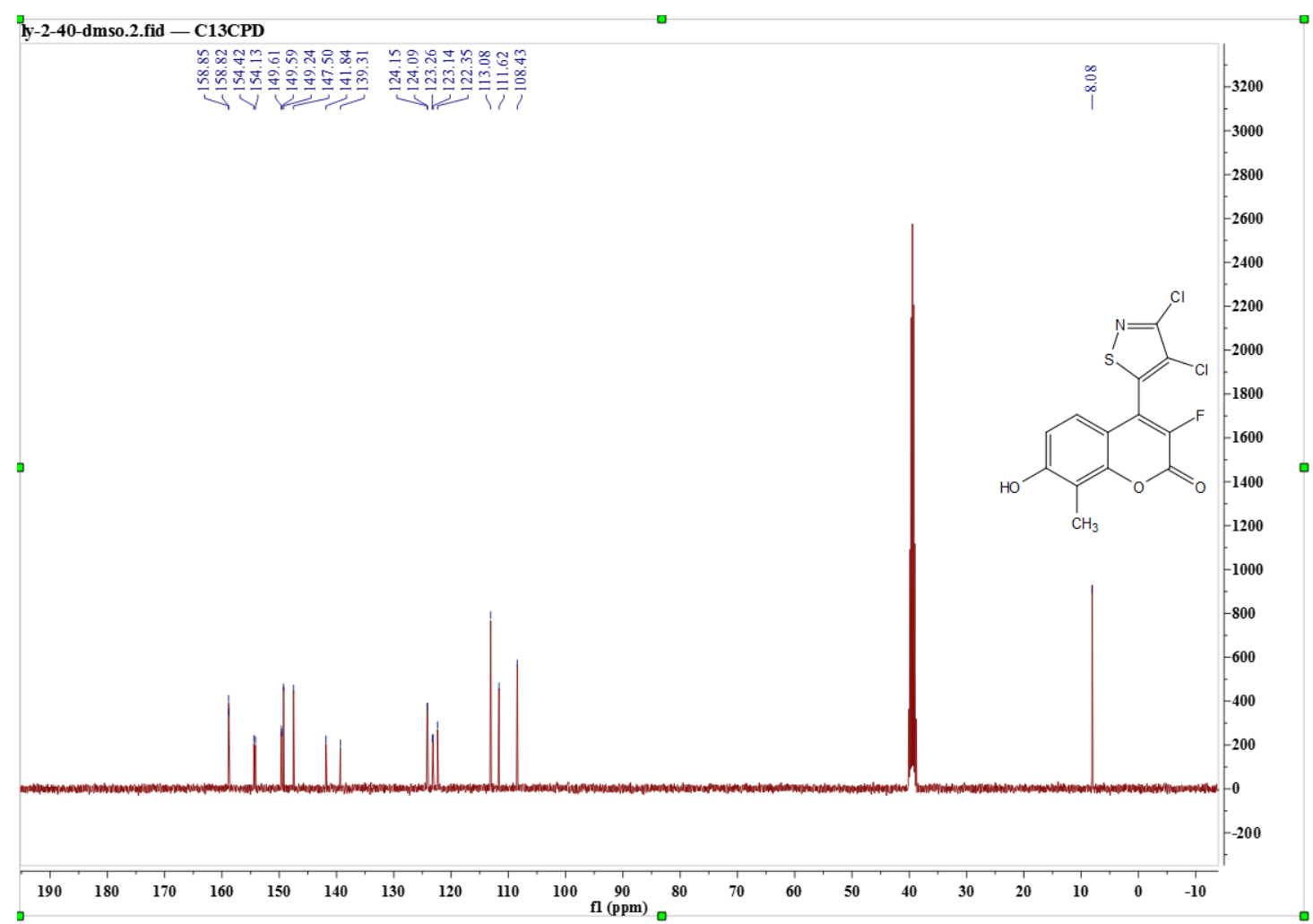

Figure S46. The ${ }^{13} \mathrm{C}$ NMR (101 MHz, DMSO- $\left.d 6\right)$ of compound 7q. 


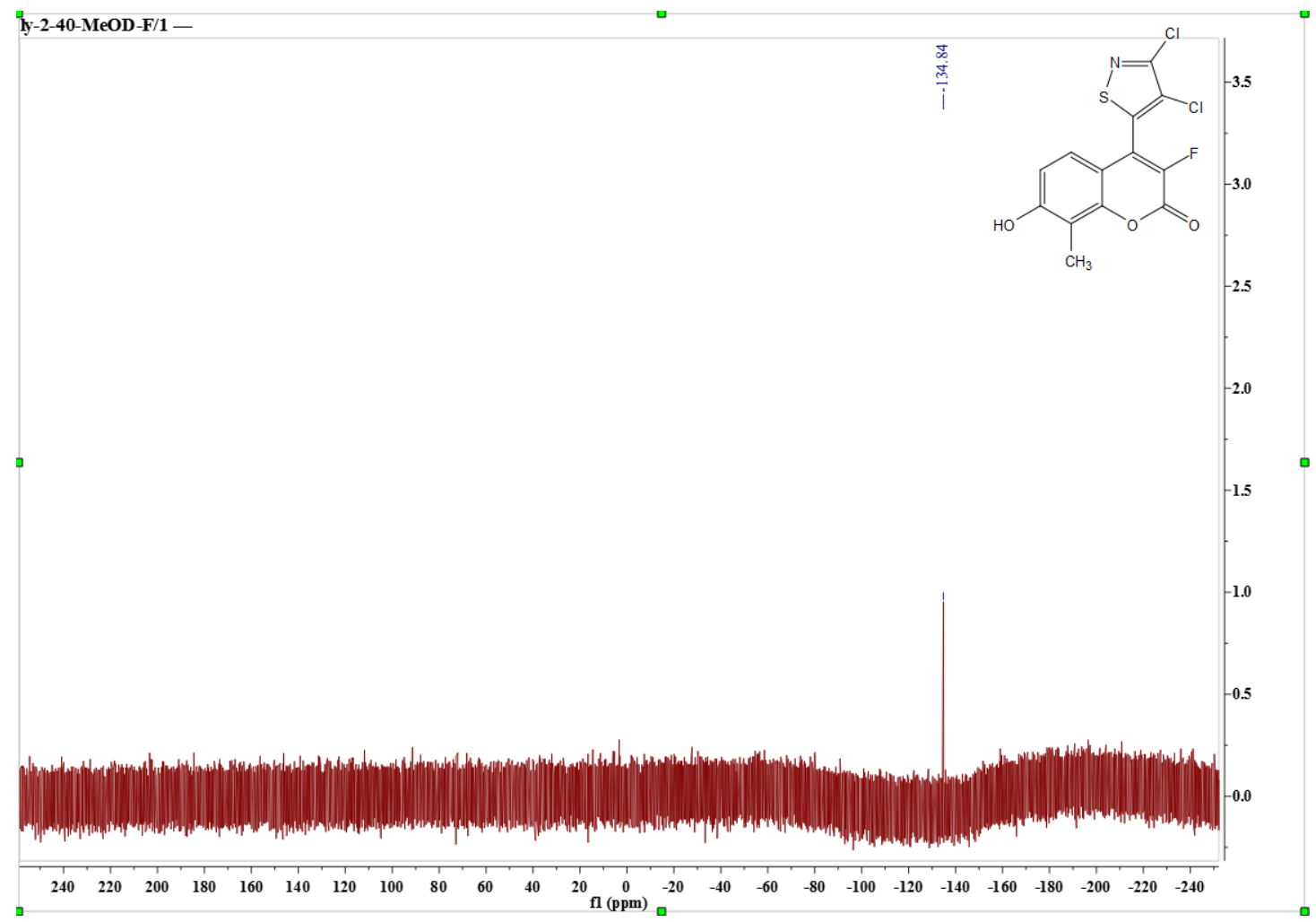

Figure 547 . The ${ }^{19} \mathrm{~F}$ NMR (376 MHz, $\left.\mathrm{CD}_{3} \mathrm{OD}\right)$ of compound $7 q$.

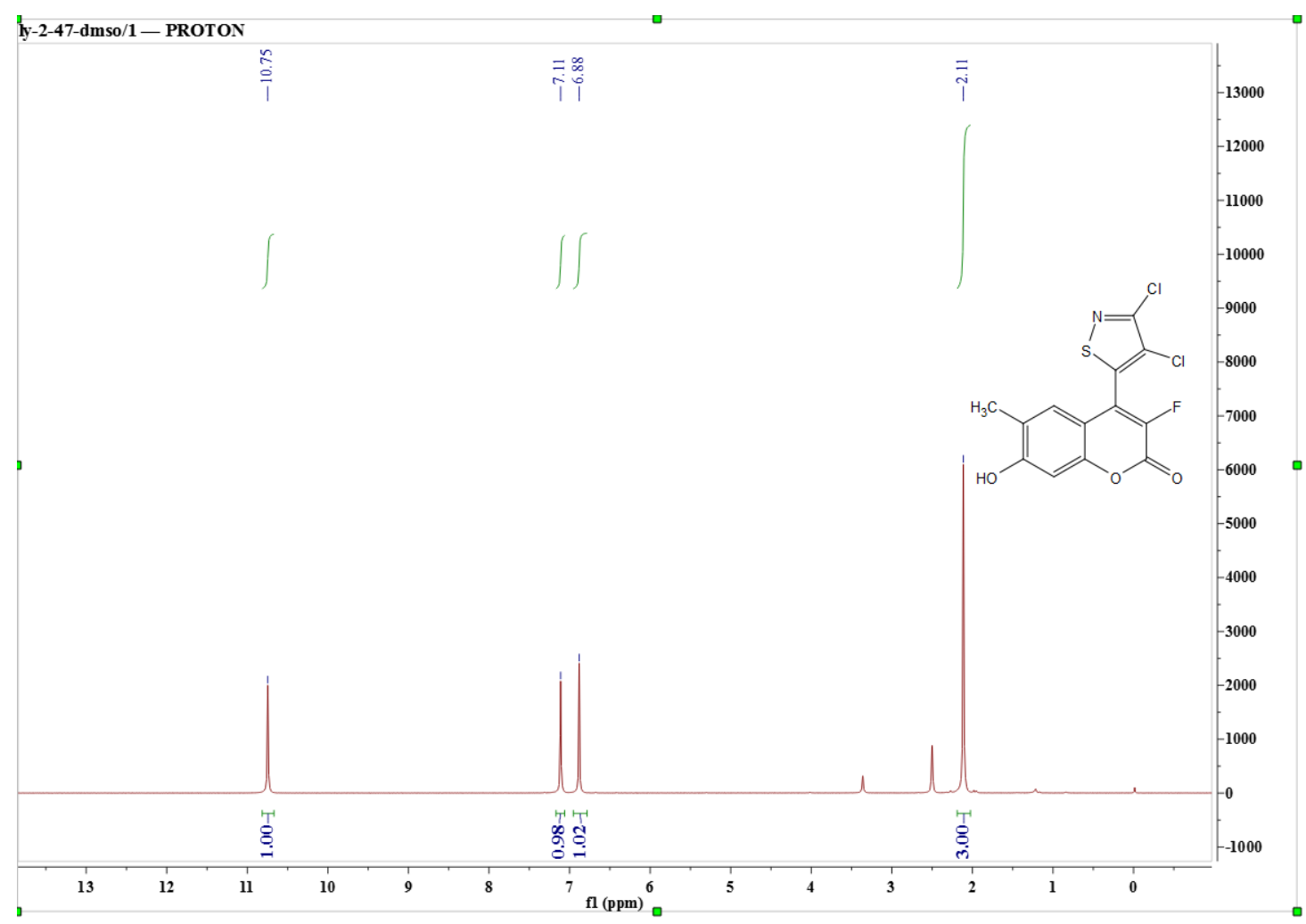

Figure S48. The ${ }^{1} \mathrm{H}$ NMR (400 MHz, DMSO-d6) of compound 7r. 


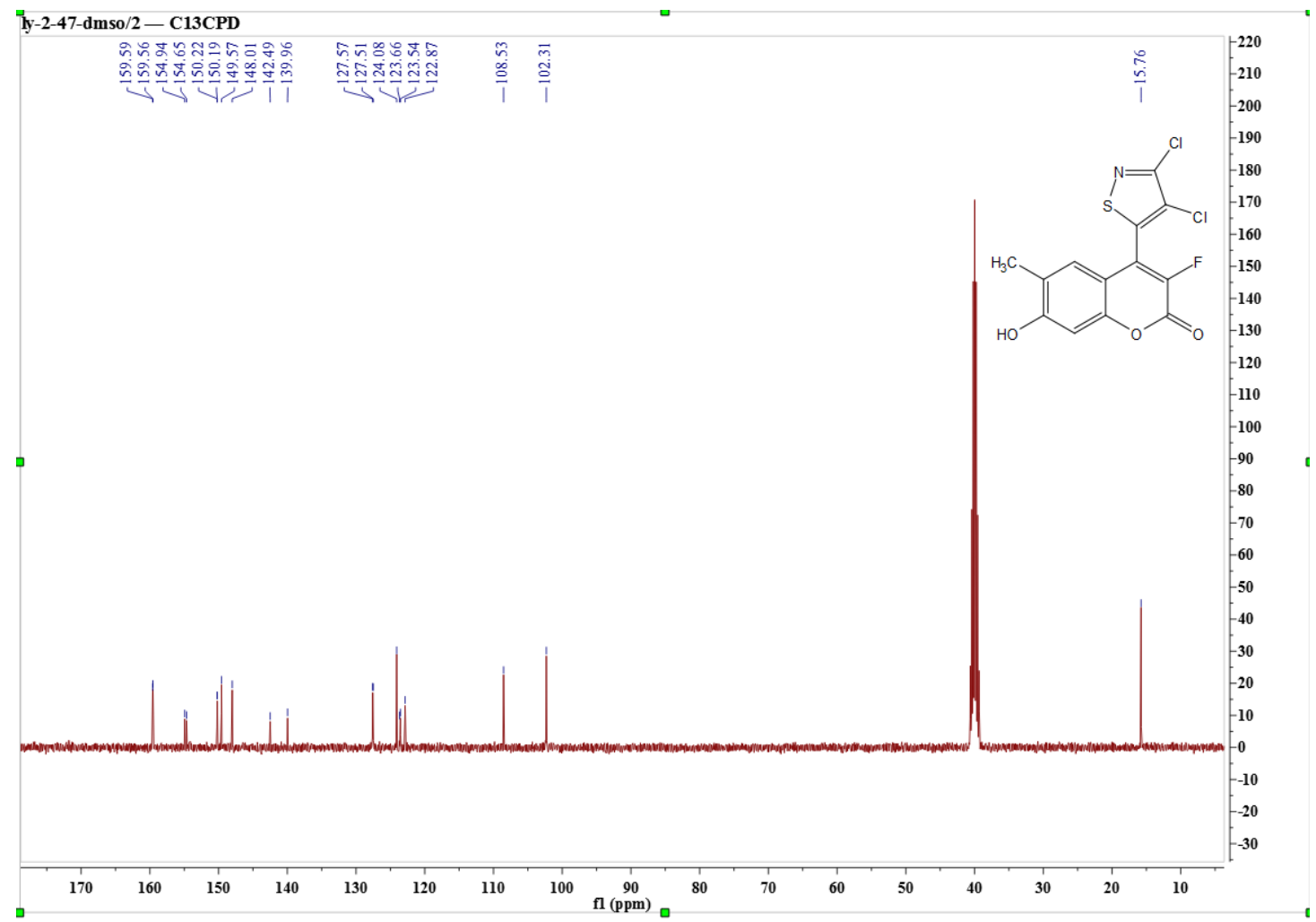

Figure S49. The ${ }^{13} \mathrm{C}$ NMR (101 MHz, DMSO-d6) of compound 7r.

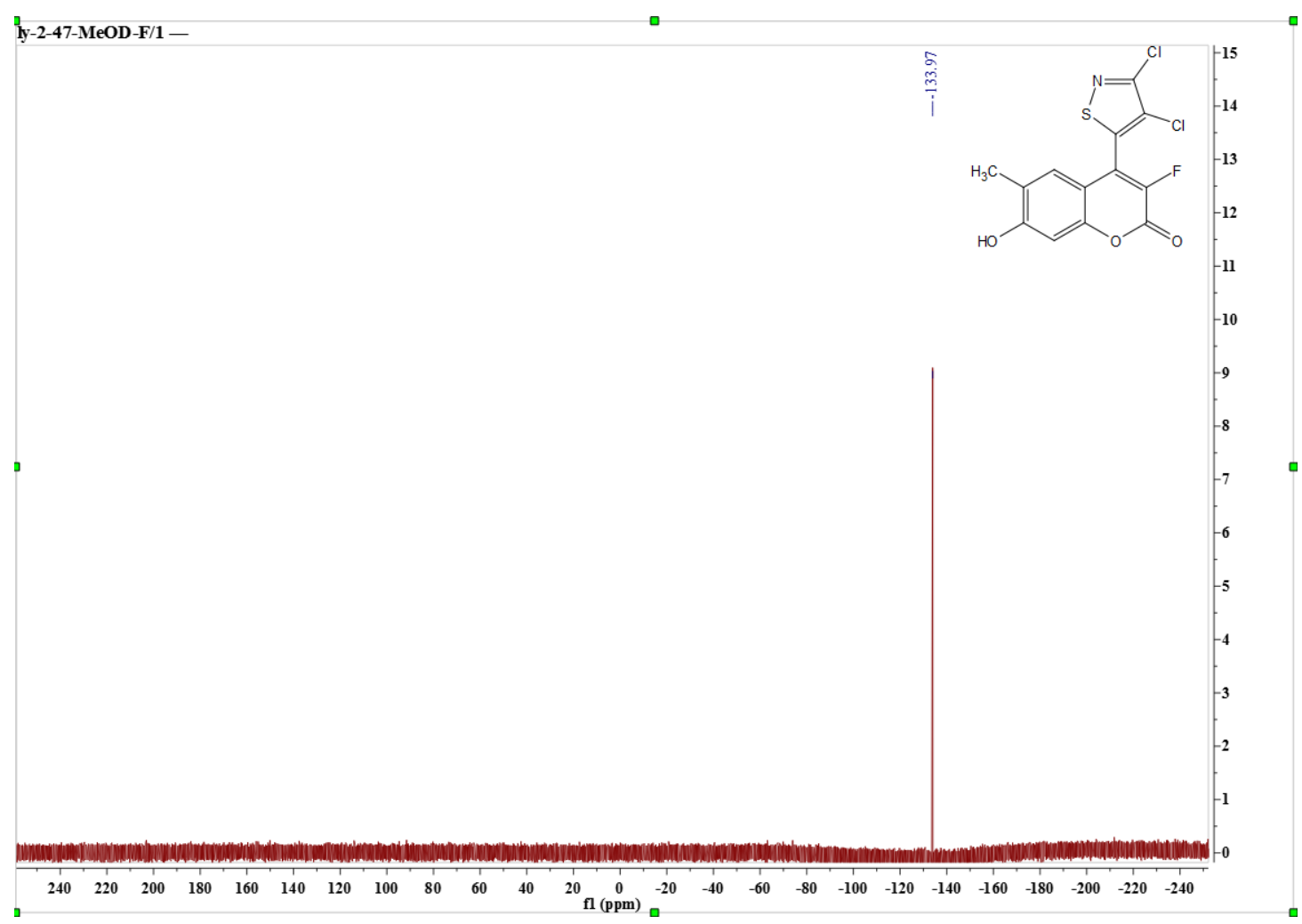

Figure S50. The ${ }^{19} \mathrm{~F}$ NMR $\left(376 \mathrm{MHz}, \mathrm{CD}_{3} \mathrm{OD}\right)$ of compound $7 \mathbf{r}$. 